OPEN ACCESS

Edited by:

Rui Yang,

Tsinghua University, China

Reviewed by:

Rita Bacelar Figueira,

University of Minho, Portugal

Costas Adam Charitidis,

National Technical University

of Athens, Greece

${ }^{*}$ Correspondence:

Jiming $\mathrm{Hu}$

kejmhu@zij.edu.cn

Huimin Meng

menghm16@126.com

Specialty section:

This article was submitted to

Environmental Materials,

a section of the journal

Frontiers in Materials

Received: 13 December 2019

Accepted: 12 March 2020

Published: 15 April 2020

Citation:

Yu Z, Hu J and Meng H (2020) A Review of Recent Developments in Coating Systems for Hot-Dip

Galvanized Steel. Front. Mater. 7:74.

doi: 10.3389/fmats.2020.00074

\section{A Review of Recent Developments in Coating Systems for Hot-Dip Galvanized Steel}

\author{
Zhen $\mathrm{Yu}^{1}$, Jiming $\mathrm{Hu}^{2 *}$ and Huimin Meng ${ }^{1 *}$ \\ ${ }^{1}$ Corrosion and Protection Center, Institute for Advanced Materials and Technology, University of Science and Technology \\ Beijing, Beijing, China, ${ }^{2}$ Department of Chemistry, Zhejiang University, Hangzhou, China
}

It is highly vital in automotive body, high-speed rail overhead line parts, and water distribution systems to use hot-dip galvanized steel (HDGS) coatings for efficiency and ease of synthesis. Various novel coating systems could surpass the technical restrictions of traditional anticorrosion techniques. Because of this, inorganic or organic coating systems must be chosen accurately and suitably. Meanwhile, these coating systems should be evaluated in accordance with their unique material characteristics and synergistic electrochemical parameters. From this view, we summarize an overview of recent developments of anticorrosive coating systems research for HDGS. First, we demonstrate the traditional protective coatings to match the use of HDGS. Likewise, emerging and state-of-the-art protective coatings are summarized. Then, methods for the assessment criteria of traditional and emerging protective coatings are displayed and illustrated through electrochemical analysis. For the conclusion, we make a proposal about the future developments of protective coating systems for HDGS.

\section{Keywords: coating, hot-dip galvanized steel, lifetime, electrochemical impedance spectroscopy, surface treatment}

\section{INTRODUCTION}

Corrosion of steel is inevitable in both production and daily life. The total economic loss caused by corrosion is estimated to be over 3\% of GDP in each country annually (Koch et al., 2002). Accordingly, it is vital to conduct coating protection for steel. To date, Zinc and its alloy provide the most effective corrosion protection for steel (Maeda, 1996; Krylova, 2001). Galvanizing layer firstly serves as a barrier coating to prevent corrosive mediums such as $\mathrm{Cl}^{-}$ions from penetrating into the matrix steel. This accumulation of the zinc corrosion products would further enhance the barrier action of the galvanizing layer. Furthermore, the galvanizing layer can act as a sacrificial anode, which zinc would preferentially corrode compared to the steel (Maaß et al., 2011; Schulz and Thiele, 2012). However, the above-mentioned HDGS has certain drawbacks, such as relatively inadequate protection performance to cope with the increasingly harsh natural environment. As an alternative, a new strategy involving the combination of the pretreatment layer and organic coating, called duplex coatings, have been proposed (Dallin et al., 2018; Svoboda et al., 2018). Therefore, the exploration of novel duplex coatings has become a hot issue. 
Typically, the pretreatment layer is a chromate or phosphate coating, which is environmentally unfriendly. Hence, there has been increased interest in the design and improvement of "green" pretreatment technology (Van Schaftinghen et al., 2004). New pretreatment layers, such as silane film (Van Ooij et al., 2000), rare-earth conversion film (Tianlan and Ruilin, 2009), conductive polymer (Le et al., 2001), and self-assembled film (Yamamoto et al., 1993) etc., have been booming during the past years. In order to fully realize the potential of these new technologies, a suitable pretreatment layer must be precisely selected and evaluated with respect to their special physicochemical properties and synergistic electrochemical parameters. Nevertheless, there is little literature evaluating the lifetime of the duplex coatings. Based on the aforementioned facts, we are eager to summarize an overview of recent HDGS research from the following three aspects: (1) anticorrosion control of zinc coatings to meet HDGS applications, (2) emerging and state-of-the-art duplex coatings for HDGS, (3) the life evaluation of aforementioned coating systems. Finally, future developments of coating systems have been proposed.

\section{ANTICORROSION CONTROL OF ZINC COATINGS TO MEET HDGS APPLICATIONS}

Zinc is an amphoteric metal. There is a large number of research articles on the corrosion mechanism of zinc in neutral solution (Cachet et al., 2001, 2002; Dafydd et al., 2005). It is generally believed that zinc is transformed by two or three intermediate substances in the corrosion process. Cachet et al. (2001) used EIS to study the corrosion process of zinc in an aerated sulfate solution and discovered that inductive reactance at a low frequency tail appear in the impedance spectra. They believed that it was related to the transformation of three adsorbed particles formed in the corrosion process of zinc, namely $\mathrm{Zn}+\mathrm{ad}$, $\mathrm{Zn} 2+\mathrm{ad}$, and $\mathrm{ZnOH}$ ad. $\mathrm{Zn}$ firstly loses an electron and becomes $\mathrm{Zn}+$ ad. Then $\mathrm{Zn}$ goes through the following three conversion paths:

$$
\begin{aligned}
& \text { Path 1: } \mathrm{Zn}+\mathrm{Zn}_{\mathrm{ad}}^{+} \rightarrow \mathrm{Zn}_{\mathrm{sol}}^{2+}+\mathrm{Zn}_{\mathrm{ad}}^{+}+2 \mathrm{e}^{-} \\
& \text {Path 2: } \mathrm{Zn}_{\mathrm{ad}}^{+} \rightarrow \mathrm{Zn}_{\text {sol }}^{2+}+\mathrm{e}^{-} \rightarrow \mathrm{Zn}_{\text {sol }}^{2+} \\
& \text { Path 3: } 2 \mathrm{Zn}+2 \mathrm{H}_{2} \mathrm{O} \rightarrow 2 \mathrm{Zn}_{\text {sol }}^{2+}+2 \mathrm{ZnOH}_{\mathrm{ad}}+\mathrm{H}_{2} \\
& \mathrm{ZnOH}_{\mathrm{ad}} \rightarrow \mathrm{ZnOH}_{\mathrm{sol}}^{2+}+\mathrm{e}^{-}
\end{aligned}
$$

Keddam et al. (1992) found that the main corrosion products of zinc in chlorine-abundant environments were basic zinc chloride, basic zinc carbonate, and zinc oxide. Under air and sodium chloride existing neutral conditions, the corrosion reaction of zinc is:

$$
\begin{gathered}
\mathrm{Zn} \rightarrow \mathrm{Zn}^{2-}+2 \mathrm{e}^{-} \\
\mathrm{O}_{2}+2 \mathrm{H}_{2} \mathrm{O}+4 \mathrm{e}^{-} \rightarrow 4 \mathrm{OH}^{2-} \\
2 \mathrm{Zn}+\mathrm{O}_{2}+2 \mathrm{H}_{2} \mathrm{O} \rightarrow 2 \mathrm{Zn}(\mathrm{OH})_{2}
\end{gathered}
$$

As the corrosion proceeds, the following corrosion reactions will also occur in the anode region.

$$
\begin{gathered}
5 \mathrm{Zn}+2 \mathrm{Cl}^{-}+8 \mathrm{H}_{2} \mathrm{O} \rightarrow \mathrm{Zn}_{5}(\mathrm{OH})_{2} \mathrm{Cl}_{2}+8 \mathrm{H}^{+} \\
\mathrm{Zn}^{2+}+2 \mathrm{Cl}^{-} \rightarrow \mathrm{ZnCl}_{2} \\
4 \mathrm{Zn}(\mathrm{OH})_{2}+\mathrm{ZnCl}_{2} \rightarrow \mathrm{Zn}_{5}(\mathrm{OH})_{8} \mathrm{Cl}_{2}
\end{gathered}
$$

In neutral or alkaline environments, basic zinc chloride will precipitate on the surface of substrates to protect matrixes from corrosion, but in acidic environments it can be easily dissolved. Therefore, basic zinc chloride can be easily washed away by rain under exposure environments. This is a cause of zinc pitting (Cachet et al., 2002). Another cause of zinc pitting in the presence of $\mathrm{Cl}^{-}$is the $\mathrm{pH}$ gradient. Cole et al. (2010) researched the corrosion products of seawater droplets interacting with zinc after short-term exposure. It was discovered that the oxide layer gradually thickened and began to significantly hinder the diffusion of ions, which would lead to the local acidification in the anode region. This could also cause pitting at the local defect site of acidification, which occurred along grain boundaries.

Carbon dioxide is another key factor that affects the corrosion of zinc. Except for zinc hydroxide, carbonate of zinc is the most widely existing corrosion product of zinc. The main forms of the carbonate of zinc are $\mathrm{ZnCO}_{3}$ and $\mathrm{Zn}_{5}\left(\mathrm{CO}_{3}\right)_{2}(\mathrm{OH})_{6}$ (Chen et al., 2006; Persson et al., 2007). The corrosion reactions are:

$$
\begin{gathered}
\mathrm{ZnO}+\mathrm{CO}_{2} \rightarrow \mathrm{ZnCO}_{3} \\
\mathrm{Zn}(\mathrm{OH})_{2}+\mathrm{CO}_{2} \rightarrow \mathrm{ZnCO}_{3}+\mathrm{H}_{2} \mathrm{O} \\
3 \mathrm{Zn}(\mathrm{OH})_{2}+2 \mathrm{ZnCO}_{3} \rightarrow \mathrm{Zn}_{5}\left(\mathrm{CO}_{3}\right)_{2}(\mathrm{OH})_{6}
\end{gathered}
$$

Basic zinc carbonate would be attached to the surface of substrates to prevent ions from diffusion and reduce the corrosion rate of substrates. It was found that the corrosion rate of zinc would increase with the increase of the concentration of $\mathrm{CO}_{2}$ (Falk et al., 1998). In addition, a large number of $\mathrm{SO}_{2}, \mathrm{NO}_{\mathrm{x}}$, and other pollutants in industrial environments will also significantly affect the corrosion of zinc. $\mathrm{SO}_{2}$ is a major contributor to acid rain and is prone to cause uniform corrosion of zinc. In an environment where $\mathrm{SO}_{2}$ coexists with $\mathrm{NaCl}$, there would be a synergistic effect between them that would result in severe corrosion of zinc (Qu et al., 2002).

In addition, the corrosion mechanism of zinc in highly alkaline environments, especially in reinforced concrete, has been extensively researched. In the initial service period, the pores of concrete are mainly saturated calcium hydroxide solution. When the $\mathrm{pH}$ value is $12 \sim 14$ (Yeomans, 2004), the galvanized layer is basically in a passivation state. Among the factors leading to the corrosion of HDGS reinforcement, $\mathrm{CaCO}_{3}$ generated from the neutralization reaction of $\mathrm{CO}_{2}$ in the air with $\mathrm{Ca}(\mathrm{OH})_{2}$ in the pore fluid of the concrete and $\mathrm{Cl}^{-}$have the most serious impacts (Al-Mehthel et al., 2009; Manna, 2009). HDGS concrete is in a passivation state at saturated $\mathrm{Ca}(\mathrm{OH})_{2}$ solution with a $\mathrm{pH}$ of $12 \sim 13$. The corrosion current density $I_{\text {corr }}$ is close to the passivation critical value. When the $\mathrm{pH}$ exceeded 13.5 , the corrosion current density $I_{\text {corr }}$ would increase rapidly on account of the absence of protective film. When the $\mathrm{pH}$ is less than nine, 
the galvanizing film could directly produce a hydrogen evolution reaction and, thus, damage the coating's structure.

When $\mathrm{Cl}^{-}$enters the concrete environment, it destroys the primary corrosion product film (consisting of calcium zincate) covered on the galvanized layer, making the galvanized layer reenter into an activation state. When the concentration of $\mathrm{Cl}^{-}$ is less than the critical value $(0.4 \sim 0.5 \mathrm{~mol} / \mathrm{L})$, the passivation film would be slightly pitted by $\mathrm{Cl}^{-}$in local region of calcium zincate with weak protection, and another corrosion product basic zinc chloride could be generated in local micro-regions. In the dense area covered by calcium zincate, pitting of $\mathrm{Cl}^{-}$will not occur. The local continuous basic zinc chloride formed by pitting, together with the large area dense calcium zincate, can still offer better protection to the galvanized layer. When the concentration of $\mathrm{Cl}^{-}$is greater than or equal to the critical value, the degree of corrosion of the galvanized layer would increase, and the penetration of $\mathrm{Cl}^{-}$to the passivation film will change from pitting corrosion to local corrosion. With the increase of $\mathrm{Cl}^{-}$concentration, a large amount of loosely deposited basic zinc chloride was generated in the area where the protection of calcium zincate was relatively weak. The basic zinc chloride was not tightly bound to the surface of the galvanized layer and it was easy to break off. $\mathrm{Cl}^{-}$would continuously infiltrate into the bottom of calcium zincate from the shed, and gradually destroy the dense membrane structure of calcium zincate, so as to expand the corrosion of the galvanized layer and destroy the matrix metal (Yeomans, 2004).

Currently, a relatively mature hot-dip galvanizing process technique for HDGS has been employed that could compete against cold galvanizing and zinc thermal spraying, which has enormous benefits over the latter. For instance, hotdip galvanizing has the advantages of lower processing costs, comprehensive protection, less labor and time, and more durability and reliability (Schulz and Thiele, 2012). There are various factors that affect the properties of zinc coatings, such as the type of steel, surface preparation of steel before galvanizing, alloying additives of zinc baths, temperature and duration of the galvanizing process, and galvanizing post cooling methods (Chen et al., 1992; Strutzenberger and Faderl, 1998; Sere et al., 1999; Morimoto et al., 2002; Safaeirad et al., 2008; Tsai et al., 2010). Hence, there are also certain challenges, result from the demands for hot-dip galvanizing process applied for HDGS. These challenges include: looking for suitable alloying elements to improve the corrosion resistance of coatings, achieving an environmental-friendly galvanizing process, and realizing an excellent adhesion with a more uniform coating. Therefore, the discovery of an optimal hot-dip galvanizing process will be applied into the corrosion protection of steel. This hot topic will open up new paths for research collaborations between the fields of metallurgy and materials science.

Furthermore, with a view to better corrosion control of the novel hot-dip galvanizing process, the following aspects should be taken into consideration to discover more appropriate hotdip galvanizing process for HDGS. As demonstrated in Figure 1, the common corrosion control strategy for matching hot-dip galvanizing process to HDGS should cover the following issues: (1) the optimal selection of a suitable matrix steel, (2) the

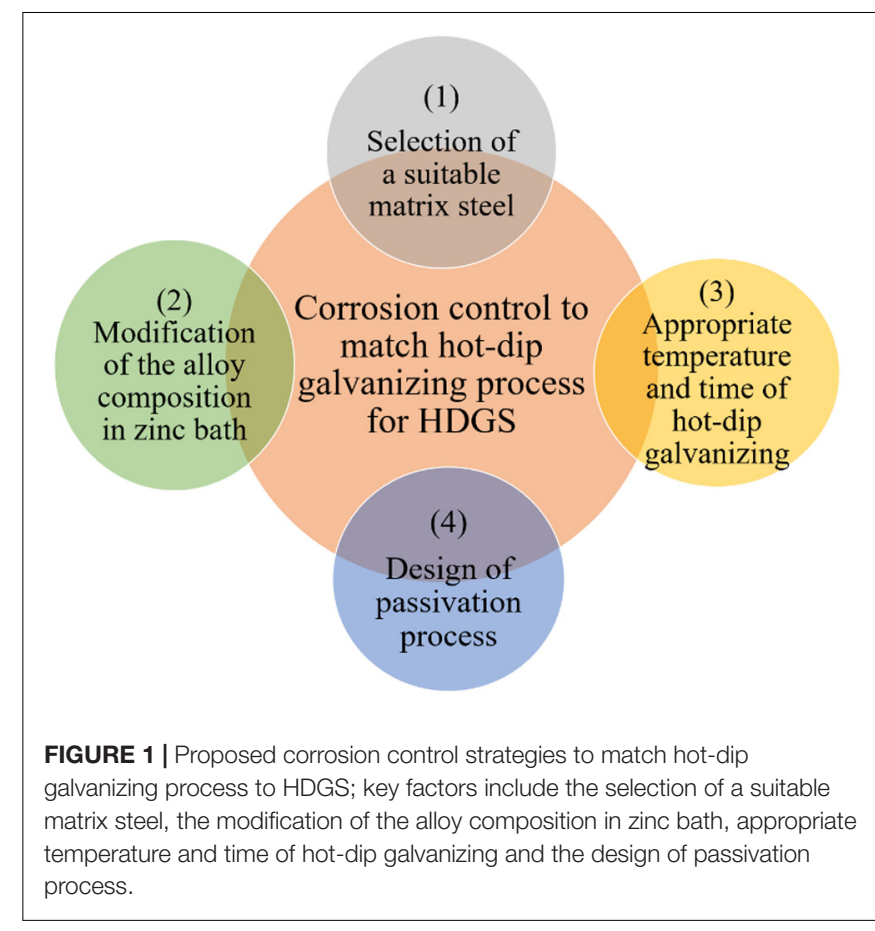

appropriate modification of the alloy composition in zinc bath, (3) suitable temperature and time of hot-dip galvanizing, (4) the adoption of passivation process. First, a suitable matrix steel should be precisely chosen. The anticipated galvanizing coating after zinc immersion can be realized when cooperating with a proper type of steel. In fact, the microstructure and mechanical property of prepared galvanized coatings would be significantly influenced by the chemical composition of matrix steel (Breval and Rachlitz, 1988; Lin, 1999; Vourlias et al., 2004; Vincent et al., 2006; Maaß et al., 2011; Schulz and Thiele, 2012; Kania and Liberski, 2014; Pokorny et al., 2016). The content of carbon and silicon in the matrix played a guiding role on the coating properties, meanwhile the component of manganese, phosphorus, and sulfur had relatively little impact on it. For example, different forms of carbon element would have different effects on the reaction between $\mathrm{Fe}$ and $\mathrm{Zn}$. When carbon was in the form of spherical pearlite and lamellar pearlite, it will accelerate the $\mathrm{Fe}-\mathrm{Zn}$ reaction. However, the reaction velocity of $\mathrm{Fe}-\mathrm{Zn}$ would not be influenced as $\mathrm{C}$ element existed as tempered martensite or graphite. Besides, the higher the content of $\mathrm{C}$ element, the faster the $\mathrm{Fe}-\mathrm{Zn}$ reaction. The acceleration of the Fe- $\mathrm{Zn}$ reaction would reduce mechanical properties of the galvanizing coating. Therefore, low carbon steels are often chosen as matrix steel. Moreover, the presence of Si element can accelerate the dissolution rate of $\mathrm{Fe}$ in a zinc bath. Steel containing a low content of $\mathrm{Si}$ could obtain a more dense resistance coating after the process of galvanizing. The higher content of Si element in steel will lead to the Sandelin effect, making $\zeta$ phase (brittle phase) grow intensely and form a gray coating with poor adhesion, which would significantly affect the appearance, microstructure, and properties of the galvanizing coating. That is to say, the exploration of a suitable chemical 
composition of steel will be the first step in the control of hot-dip galvanizing process. Second, modification of the alloy composition in zinc bath for a prescribed matrix steel plays an essential role in galvanizing optimization (Fasoyinu and Weinberg, 1990; Pavlidou et al., 2005; Asgari et al., 2007; Pistofidis et al., 2007; Culcasi et al., 2009). Particularly, the melting point, viscosity, and surface tension of zinc bath can be modified by some certain alloying elements, so that the coating thickness, surface gloss, and mechanical strength of HDGS can be tuned for the better. In consequence, modifying alloy compositions by introducing different alloying elements, such as $\mathrm{Al}, \mathrm{Mg}$, or $\mathrm{Ni}$, can enhance the corrosion resistance of the galvanizing coating. Besides, addition of rare earth elements or Sb can also improve the fluidity of zinc bath and reduce the amount of zinc adhesion on the surface of HDGS. Sb has a relatively poor solubility in zinc bath, which will precipitate as $\mathrm{Sb}_{3} \mathrm{Zn}_{4}$. Thus, galvanic cells of $\mathrm{Sb}_{3} \mathrm{Zn}_{4} / \mathrm{Zn}$ will be formed. An adherent coating is deposited with the addition of $\mathrm{Sb}$ through barrier and galvanic protection (Peng et al., 2020). Third, an appropriate temperature and time for hot-dip galvanizing is another key factor to optimize or regulate the as-prepared galvanizing coating to improve the hot-dip galvanizing process (Fasoyinu and Weinberg, 1990; Asgari et al., 2007; Culcasi et al., 2009). Whether the temperature of zinc bath is too high and too low, it will have adverse effects on the coating properties. As for the hot-dip galvanizing time, it is necessary to shorten the dip time under the premise of ensuring a certain coating thickness, which could decrease the thickness of $\zeta$ phase and improve the plasticity of gal izing coating. Fourth, an effective passivation process is also beneficial to optimize the galvanizing coating. Chromate passivation technology, on account of its simple process, low cost, and good film adhesion, is a classic process typically used to improve the corrosion resistance of HDGS (Van Schaftinghen et al., 2004). Unfortunately, chromate coating is highly carcinogenic and toxic. Therefore, for safety and environmental reasons, some low-toxic or non-toxic treatments have also been developed in recent years. The optimal galvanizing coating originating from such chromate passivation enriches the large family of hot-dip galvanizing process and fulfills different demands for HDGS.

\section{EMERGING AND STATE-OF-THE-ART DUPLEX COATINGS FOR HDGS}

Emerging and state-of-the-art coating protection systems are normally made from an appropriate matrix steel with duplex coatings, generally consisting of a metallic zinc coating with a pretreatment layer followed by an organic coating. Up to now, plenty of novel and prospective duplex coatings have been discovered, modified, or further developed, which have certified their feasibility in corrosion resistance of HDGS. In the light of forms of the pretreatment layers, these duplex coatings cover silane films (Subramanian and Van Ooij, 1998; Van Ooij and Child, 1998; Van Ooij et al., 2000; van Ooij and Zhu, 2001), rareearth conversion films, conductive polymers, and self-assembled films. A good deal of novel duplex coatings have been invented successfully by conducting different pretreatments on the matrix of HDGS. Table 1 lists four types of typical duplex coating systems for HDGS. Therefore, we will summarize these abovementioned emerging and state-of-the-art duplex coatings in accordance with the category of their pretreatment technologies.

\section{Silane Films}

The most famous silane film is no doubt bis-1,2[triethoxysilyl] ethane (BTSE) with a functional silane such an $\gamma$-Ureidopropyltriethoxysilane $(\gamma$-UPS $)$ or $\gamma$-aminopropyltriethoxysilane ( $\gamma$-APS) (Van Ooij et al., 2000). Stable covalent bonds between metallic substrate and silanes can be formed by dehydration of hydrogen bonds. Besides, functional silanes can improve the integrity of formed film. Therefore, compact silane film can supply highly effective barrier protection (Chang et al., 2019). Figure 2 displays the composition of a coating system after a typical film-forming process of BTSE. As illustrated in Figure 2, a thin silicate conversion layer, consisting of the general type $[\mathrm{Me}-\mathrm{O}]_{\mathrm{x}}\left[\mathrm{SiO}_{3} \mathrm{X}\right]_{y}$, is firstly formed. Subsequently, a condensed silane layer is formed. After that, an interpenetrating coating is formed between the condensed silane and the cross-linked organics. Numerous micro cells would be formed at the interface of solution/substrate when HDGS was immersed into silane solution. The micro-anode and micro-cathodic reactions, respectively were the dissolution of zinc and the reduction of oxygen, which could result in the local increase of $\mathrm{pH}$ in the micro-cathodic region. With the further increase of micro-electrochemical reaction, zinc hydroxides would be generated and deposited at solution/substrate interface. Synchronously, hydrogen bonds between $\mathrm{Si}-\mathrm{OH}$ groups, originating from the solution and zinc hydroxides, would be framed via hydrolyzed silanes. Moreover, silane can interact with each other through hydrogen bonding. After the curing process, $\mathrm{Zn}-\mathrm{OH}$ and $\mathrm{Si}-\mathrm{OH}$ groups would be further condensed to form $\mathrm{Zn}-\mathrm{O}$-Si bonds. In addition, $\mathrm{Si}-\mathrm{OH}$ groups would also cross-link to form Si-O-Si covalent bonds ( $\mathrm{Li}$ et al., 2020). Prerequisites for the formation of this are the compatibilities of interface wettability and surface energy. Not all functional groups can improve the compatibility, hence choosing appropriate and effective functional groups becomes a difficulty that needs to be overcome urgently. The stronger the compatibility, the stronger the adhesion between silane and organics. Therefore, the final coating system would strongly prevent water and corrosive ions permeating into metal as a result of forming a well-bonded hydrophobic interface between the condensed silane and organics. However, the combination of BTSE and functional silanes is not universal for different metals (Van Schaftinghen et al., 2004; Zhu and van Ooij, 2004). Every metal almost requires a very specific silane component to meet the needs for corrosion inhibition. Consequently, a more universal silane composition, which is not sensitive to the substrate metal, could have greater application prospects.

Highly acceptable silane mixture of bis-1,2[trimethoxysilylpropyl]amine (BTSPA) and bis-1,2[triethoxysilylpropyl] tetrasulfide (BTSPS) is another modified kind of silanes, which was firstly reported by Zhu and van Ooij (2004). It can be used to effectively protect different kinds of metals (such as stainless steel, HDGS, electro galvanized steel, 
TABLE 1 | Typical duplex coatings applied to HDGS.

\begin{tabular}{|c|c|c|c|c|}
\hline Category & Author & Year & System & References \\
\hline \multirow[t]{16}{*}{ Silane films } & Van Ooij & 2004 & $\begin{array}{l}\text { mixture of bis-1,2-[trimethoxysilylpropyl]amine and } \\
\text { bis-1,2-[triethoxysilylpropyl] tetrasulfide }\end{array}$ & Zhu and van Ooij, 2004 \\
\hline & Montemor & 2004 & bis-1,2-(triethoxysilyl)ethane & Montemor et al., 2004 \\
\hline & Motte & 2012 & montmorillonite clay with $\mathrm{Ce} 3+$ & Motte et al., 2012 \\
\hline & Kartsonakis & 2012 & ceramic nanocontainers incorporated into epoxy resin & Kartsonakis et al., 2012 \\
\hline & Zhou & 2013 & polybenzoxazine & Zhou et al., 2013 \\
\hline & Van Ooij & 2013 & epoxy-resin-ester modified bis-[tri-ethoxy-silyl] ethane & Xue and Van Ooij, 2013 \\
\hline & Capelossi & 2013 & sulfursilane with $\mathrm{Ce} 4+$ & Capelossi and Aoki, 2013 \\
\hline & Seré & 2014 & mercaptopropyltrimethoxysilane & Seré et al., 2014 \\
\hline & Francisco & 2014 & sulfursilane & Francisco et al., 2014 \\
\hline & Figueira & 2014 & alcohol-aminosilicate & Figueira et al., 2014 \\
\hline & Longhi & 2015 & tetraethoxy with PMMA & Longhi et al., 2015 \\
\hline & Figueira & 2015 & mixture of 3-isociantepropyltriethoxysilane and oligopolymer & Figueira et al., 2015 \\
\hline & $\mathrm{Su}$ & 2016 & tetraethyl orthosilicate with organosilane and cerium & Su et al., 2016 \\
\hline & Bera & 2016 & $\begin{array}{l}\text { silanes with alkoxy group, epoxy group, amine group and thiol } \\
\text { group }\end{array}$ & Bera et al., 2016 \\
\hline & Chang & 2019 & tetraethyl orthosilicate and $\gamma$-glycidoxypropyltrimethoxysilane & Chang et al., 2019 \\
\hline & $\mathrm{Li}$ & 2020 & vinyltrimethoxysilane with $\mathrm{Ce} 3+$ & Li et al., 2020 \\
\hline \multirow[t]{12}{*}{ Rare-earth conversion films } & Montemor & 2001 & $\mathrm{Ce}(\mathrm{NO} 3) 3$ & Montemor et al., 2001 \\
\hline & Montemor & 2002 & RE(NO3)3, RE: Y, La, Ce & Montemor et al., 2002 \\
\hline & Montemor & 2006 & bis-silanes with $\mathrm{Ce}(\mathrm{NO} 3) 3$ or $\mathrm{La}(\mathrm{NO} 3) 3$ & Montemor et al., 2006 \\
\hline & Peng & 2009 & La(NO3)3 and trimethoxy(viny)silance & Tianlan and Ruilin, 2009 \\
\hline & Gang & 2010 & La(NO3)3 with citric acid & Gang et al., 2010 \\
\hline & Gong & 2012 & $\mathrm{Ce}(\mathrm{NO} 3) 3$ with silane coupling agent $\mathrm{KH}-570$ & Gong et al., 2012 \\
\hline & $\mathrm{Su}$ & 2016 & $\mathrm{Ce}(\mathrm{NO} 3) 3$ with organosilane & Su et al., 2016 \\
\hline & Kartsonakis & 2016 & Ce(NO3)3 and 8-hydroxyquinoline & Kartsonakis et al., 2016 \\
\hline & Zhang & 2018 & $\mathrm{La}(\mathrm{NO} 3) 3$ with $\mathrm{SiO}_{2}$ & Zhang et al., 2018 \\
\hline & Zhang & 2019 & $\mathrm{Ce}(\mathrm{NO} 3) 3$ with citric acid & Zhang et al., 2019 \\
\hline & Karaxi & 2019 & epoxy-based resin with cerium oxide or cerium ion & Karaxi et al., 2019 \\
\hline & $\mathrm{Li}$ & 2020 & $\mathrm{Ce}(\mathrm{NO} 3) 3$ with vinyltrimethoxysilane & Li et al., 2020 \\
\hline \multirow[t]{6}{*}{ Conductive polymers } & Jafarzadeh & 2011 & polyaniline doped with methane sulfonic acid & Jafarzadeh et al., 2011 \\
\hline & El-Shazly & 2011 & polypyrrole & El-Shazly and Al-Turaif, 2011 \\
\hline & Deshpande & 2012 & polyaniline & Deshpande et al., 2012 \\
\hline & Sarli & 2014 & polyurethane with $\mathrm{Cr} 3+$ or $\mathrm{Cr} 6+$ & Di Sarli et al., 2014 \\
\hline & Cuttone & 2016 & polyaniline with emeraldine base & Cuttone et al., 2016 \\
\hline & Malekzadeh & 2017 & polyaniline & Malekzadeh et al., 2017 \\
\hline \multirow[t]{4}{*}{ Self-assembled films } & Kobayashi & 2006 & phosphoric acid mono-n-dodecyl ester with Ce3+ & Kobayashi and Fujiwara, 2006 \\
\hline & El-Sayed & 2012 & phytic acid with dithio-oxamide and 2,3-dimercapto-1-propanol & El-Sayed et al., 2012 \\
\hline & Jia & 2013 & imidazole derivatives & Jia et al., 2013 \\
\hline & Obot & 2015 & benzimidazole derivatives & Obot et al., 2015 \\
\hline
\end{tabular}

aluminium alloy, and copper), making up for the shortcomings of the combination of BTSE and functional silanes. In addition, the proportion of BTSPA and BTSPS can be modified arbitrarily and the silane mixture can be hydrolyzed or non-hydrolyzed before application. A variety of organic coatings such as epoxy resins, polyurethane, polyester, and so on can be strongly bonded to mixed silane films, which would further enhance the corrosion resistance of the coating system. Furthermore, silane films doped with different nanoparticles were also prepared by their group for the purpose of improving adhesion and anticorrosive capabilities (Palanivel et al., 2003).

In high alkaline environments, silane pretreatment films for HDGS also have a wide range of applications, especially in the cement field. A stable protective film will form on the surface of HDGS at the $\mathrm{pH}$ range of 6-13, which can reduce the corrosion rate of zinc. Except for the aforementioned $\mathrm{pH}$ range, the formed protective films would be destroyed and zinc would be corroded (Roetheli et al., 1932). Figueira et al. (2013; 2014; 2015 ; 2016) had researched composite organic-inorganic coatings based on inorganic silanes, supplemented by five different organic oligomers in mortar or simulated concrete pore solution. Two typical kinds of coating systems were amino-alcoholsilicates $(\mathrm{A}(\mathrm{X}))$ and ureasilicates $(\mathrm{U}(\mathrm{X}))$. Dip-coating methods were also applied by easily depositing these functional films on HDGS. By the results of electrochemical measurements, silane films based on $\mathrm{U}(\mathrm{X})$ and oligomers exhibited superior corrosion resistance 


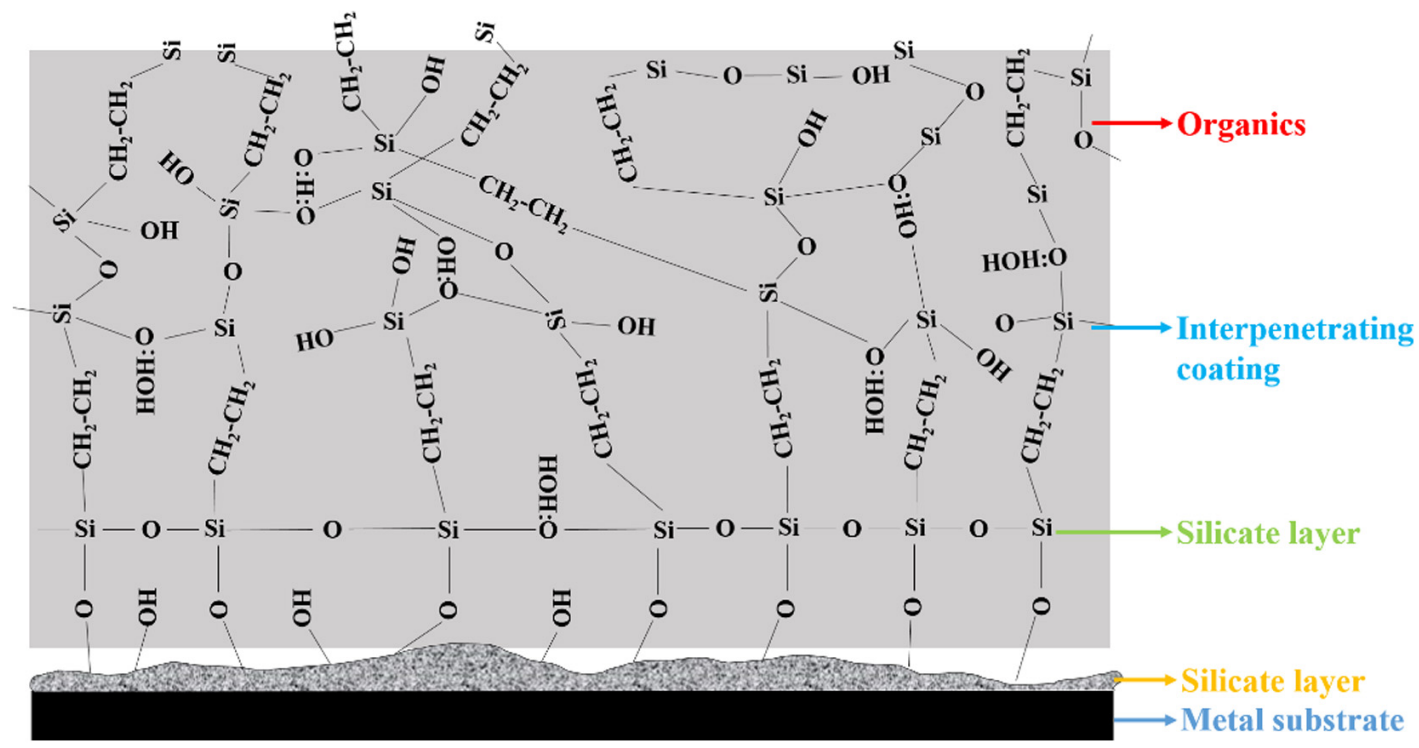

FIGURE 2 | Schematic illustration of the polymer/metal interface after film-forming process.

than that on $\mathrm{A}(\mathrm{X})$ and oligomers. In addition, the molecular weight of oligomers had a large impact on the corrosion resistance of the coated HDGS. In principle, the film would be rougher with the increase of molecular weight of oligomers. Therefore, the larger the molecular weight, the less protective the performance of films. They also investigated the effect of dip technology on the barrier protection of prepared coatings. Dip method with one, two, or three steps seemed to have no significant improvements on corrosion resistance. It must be point out that the aforementioned silane films could be simply and easily prepared through immersing substrate metal into as-prepared silane precursors solution for a certain time, and this method could be called dip-coating preparation. The drawbacks of those as-prepared films are their relative lack of uniformity, which could have side effects on the corrosion resistance of coating.

For the aim of further improving the corrosive inhibition properties of above-mentioned silane films, electrochemical deposition technology is introduced into preparing these organic silane films (Woo et al., 1993; Shacham et al., 1999; Sheffer et al., 2003; Gandhi and van Ooij, 2004). Hu's group has done numerous research on this aspect (Hu et al., 2006, 2007; Li et al., 2010; Jiang et al., 2015; Liu et al., 2017; Xu et al., 2018). Firstly, silane films were electrodeposited successfully in BTSE solutions at different deposition potentials on AA 2024-T3 alloys ( $\mathrm{Hu}$ et al., 2006). Silane films revealed an enhancement in corrosion resistance properties when deposited at cathodic potentials, on the contrary it will display an adverse effect on corrosion protection for prepared films under the circumstance of anodic potentials. As indicated in Figure 3, the corrosion protection abilities of electrodeposited silane coatings first improve and subsequently descend as the applied cathodic potentials gradually deviate from the open-circuit potential, and the optimal cathodic potential is $-0.8 \mathrm{~V} / \mathrm{SCE}$.

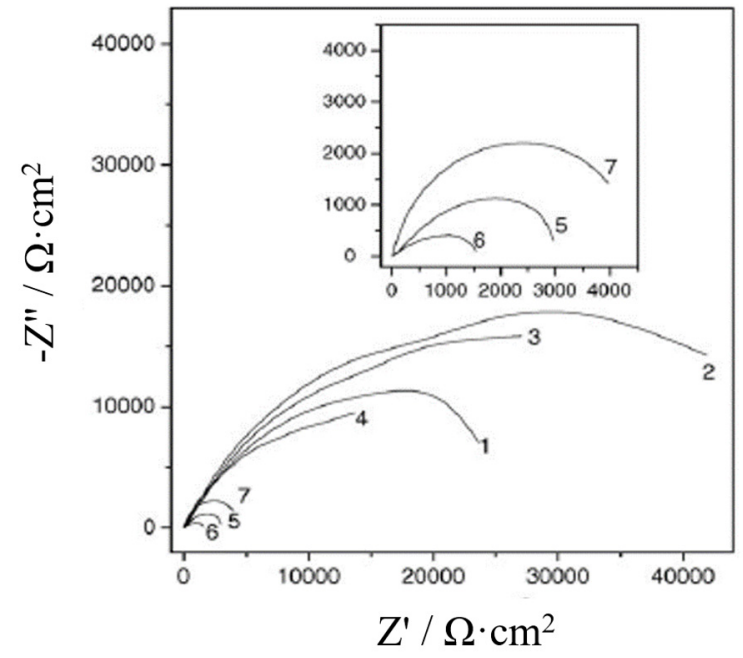

FIGURE 3 | Complex plane of uncoated (7) and BTSE coated AA 2024-T3 alloys. The silane films are deposited at OCP V/SCE (4), -0.2 V/SCE (6), -0.4 V/SCE (5), -0.6 V/SCE (3), -0.8 V/SCE (2), and -1.0 V/SCE (1) (Hu et al., 2006).

Secondly, under the circumstance of electrodeposition of silane coatings, various doping technologies are attempted to be doped into the silane films ( $\mathrm{Li}$ et al., 2010). They discovered that doped nanoparticles such as $\mathrm{SiO}_{2}$ and $\mathrm{TiO}_{2}$ can fill the defect of electrodeposited silane films. In addition, the composite of rare-earth ion and electrodeposited silane films provides a self-repairing property for obtained film (Zheludkevich et al., 2005). Co-electrodeposition of active metal and organic silane can provide additional cathodic protection for prepared 
silane films. These doping technologies can all improve the corrosion protection performance of silane films (Ferreira et al., 2004; Cabral et al., 2006; Montemor and Ferreira, 2007). As demonstrated above, all silane films are organics. The binding force of organosilane film to the coating is highly selective and is not suitable for different types of protective organic coatings. Besides, organosilane film lacks a rough and porous surface structure, which would affect the adhesion to organic paints or coatings and the quantity and quality of corrosion inhibitors load. Therefore, new-emerging electrodeposition inorganic $\mathrm{SiO}_{2}$ film comes into being ( $\mathrm{Hu}$ et al., 2006). The thickness of electrodeposition $\mathrm{SiO}_{2}$ film can reach $10 \mu \mathrm{m}$ and these films show excellent adhesion and high microscopic roughness, which is beneficial for binding to organic coatings and loading of corrosion inhibitors (Liu et al., 2017). A composite coating system containing $\mathrm{E}_{-} \mathrm{SiO}_{2}$ film loaded with corrosion inhibitors was successfully synthesized as shown in Figure 4. The prepared samples still have extremely high impedance modulus (over $10^{11} \Omega \mathrm{cm}^{2}$, at $0.01 \mathrm{~Hz}$ ) even though immersed into $3.5 \mathrm{wt} \%$ $\mathrm{NaCl}$ solution for nearly 1 year, superior to almost all highperformance duplex coatings reported in the literature up to now. It shows that this novel duplex coating system using the $\mathrm{e}-\mathrm{SiO}_{2}$ film as both pretreatment layer and container of corrosion inhibitors should have a great application prospect in the field of HDGS corrosion protection.

As a brief summary, coating systems containing silane interlayer, represented by BTSE, have exhibited giant potential and have been used in the protection against corrosion of Al alloys. However, the relatively poor compatibility and adhesion property of prepared silane films restrict its further application, especially in various steel materials. Therefore, some new silane pretreatments with improved anti-corrosion properties are still needed, such as the emerging electrodeposited organosilane and inorganic $\mathrm{SiO}_{2}$ film discussed above when applying silane film to HDGS.

\section{Rare-Earth Conversion Films}

Rare-earth conversion films also play a major role in the technological design of new pretreatments for protecting HDGS from corrosion. Particularly, rare-earth conversion films, formed by cerium salts and their modifications, have attracted great interest in respect to their potential applications
(Rudd et al., 2000; Xingwen et al., 2001; Ferreira et al., 2004; Lu et al., 2006; Montemor et al., 2008; Tianlan and Ruilin, 2009; Dan et al., 2010; Yanhua et al., 2013; Majd et al., 2019). As a basic component of rare-earth conversion film, rareearth ions can comprise relatively complex film compositions, which commonly contain a wide range of negative ions through different surface pretreatments of metal substrate, $\mathrm{PH}$ in solution, immersion time, concentrations of rare-earth ions in solution, and deposition temperature (Brachetti-Sibaja et al., 2011). It is recognized that rare earths can act as corrosion inhibitors via inhibiting cathode reactions (Karaxi et al., 2019). Among these rare-earth conversion films, films containing cerium or lanthanum ions are pervasive and their anti-corrosion properties and applications as pretreatment layers have been widely researched (Aldykewicz et al., 1995; ?; Wang et al., 2004; Kumar et al., 2012). Figure 5 gives the schematic diagram of kinetics of the cerium-based film formation (Sun et al., 2019; Li et al., 2020). The rare-earth conversion film formation process typically can be divided into three stages according to electrochemical reactione processes of different immersion time. The first stage can be referred as the rare-earth film initiation stage, wherein the surface of the metal starts to dissolve and corrosion pits appear around the metal surface accompanied with the precipitation of cerium hydroxide. Generally, the dissolution of metal occurs at the anode region (reaction $1: \mathrm{Me} \rightarrow \mathrm{Me}^{2-}+2 \mathrm{e}^{-}$). At the same time, oxygen starts to be reduced at the cathodic region (reaction 2: $2 \mathrm{H}_{2} \mathrm{O}+\mathrm{O}_{2}+4 \mathrm{e}^{-} \rightarrow 4 \mathrm{OH}^{-}$). The deposition of $\mathrm{Ce}(\mathrm{OH}) \mathrm{n}(n=3,4)$ and hydroxide of metal start to appear orderly for an increase in the $\mathrm{pH}$ at the micro-cathode area. It should be noted that a $\mathrm{pH}$ over 8.7 is necessary for the oxidation of $\mathrm{Ce}^{3+}$ to $\mathrm{Ce}^{4+}$. However, direct oxidation of $\mathrm{Ce}^{3+}$ to $\mathrm{CeO}_{2}$ is impossible. In addition, the presence of $\mathrm{H}_{2} \mathrm{O}_{2}$ can benefit the oxidation process, accelerating the formation of hydroxides and oxides of Ce (Karaxi et al., 2019). The second stage can be known as the rare-earth film formation and crack initiation stage, wherein the dissolution of metal continues along with the precipitation of hydroxide of cerium. As a consequence, the thickness of these conversion films continues to increase. In addition, partial hydroxide of these precipitations could be dehydrated into their relevant oxides in air and few cracks could appear on the film. The third stage can be referred to as crack development stage, which sees the rare-earth

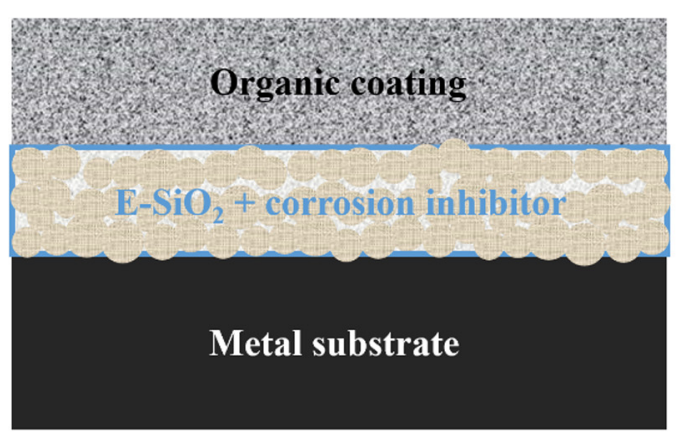

${\mathrm{E}-\mathrm{SiO}_{2}}_{2}$ : Electrodeposited silica film (about $10 \mu \mathrm{m}$ )

Corrosion inhibitor : Zinc gluconate (ZnG) or polypyrrolidone (PVP)

FIGURE 4 | Schematic diagram of composite coating system coated AA 2024-T3 alloys. 


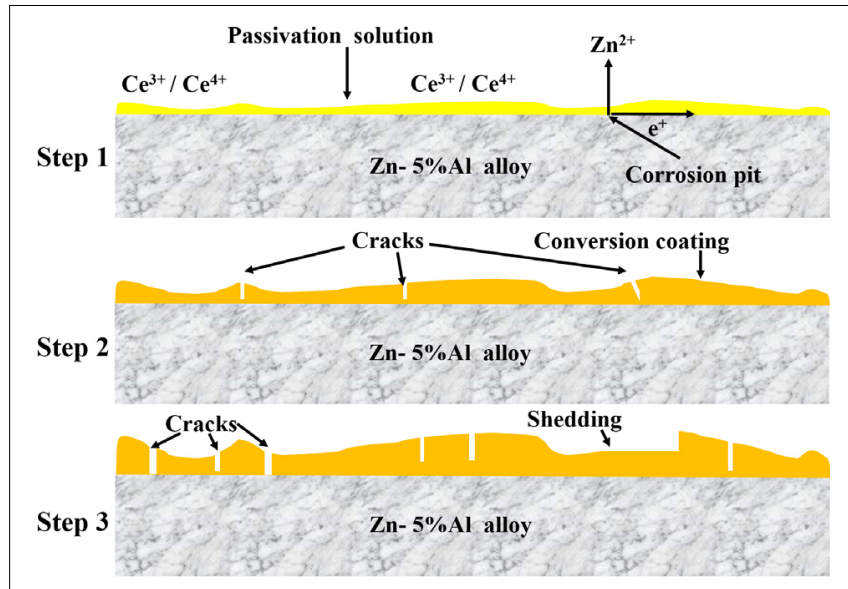

FIGURE 5 | Schematic diagram of the growth process of lanthanum-based conversion coating. passivation film become thicker as well as the cracks become deeper and wider, a partial region of the film could gradually fall off and detach.

Since Hinton and Wilson (1989) first introduced rare-earth salts-based pretreatments into corrosion protection of metals in 1989, numerous research about rare-earth conversion films have been conducted over the past decades. They discovered that oxide or hydroxide of cerium could be highly valid in restraining the corrosion rate of zinc by means of suppressing the cathodic reaction. Aramaki (2001a,b, 2005) also investigated the corrosion inhibition mechanism of cerium salts deposited on zinc. The generation of cerium sesquioxide frame network on the surface of zinc could be the cause for the inhibition of cathodic reactions. Rudd et al. (2000) researched various rareearth salts pretreatments to the corrosion effect of magnesium and its alloys. They found that these substrates, when treated with lanthanum, cerium, or praseodymium salts, would have an improved corrosion resistance in comparison with untreated samples, which could be ascribed to the coprecipitation of rare-earth hydroxyl/oxide coatings and mixed magnesium hydroxyl/oxide products. Brachetti-Sibaja et al. (2011) studied the bath conditions effect of cerium and lanthanum treatments on the corrosion protection performance of AA6061 alloy. The enhancement of anticorrosive properties of AA6061 aluminum alloy presumably is due to the improved barrier performances of the rare-earth conversion layer. Lu et al. (2006) investigated the optimal treatment technology by adjusting and controlling the immersion time of hot-dip galvanized steel (HDGS) into cerium salt solution. With the increase of the immersion time, the anti-corrosion properties of the rare-earth conversion film firstly enhance within $1 \mathrm{~h}$ on account of the thicker coating thickness therewith and then weaken after $1 \mathrm{~h}$ due to the occurrence of cracks and peeling off of the coating.

As the aforementioned demonstrates, rare-earth conversion films display a huge potential in the use of different kinds of metal's pretreatment protection. Recently, in order to cope with the deteriorating natural environment, many novel rare-earth conversion films have been discovered. For example, a two-step treatment of trimethoxy(viny) silance and lanthanum salt is used for the sake of corrosion protection of galvanized steel (Tianlan and Ruilin, 2009). This two-step method furnishes excellent paint adhesion and gives a more effective anticorrosion property than $\mathrm{Cr}^{6+}$ pretreatment alone. For aluminum alloy, the duplex rareearth conversion films (Xingwen et al., 2000) are introduced to enhance the corrosion resistance of LY12 alloy. The polarization consequences show that the corrosion resistance of the duplex conversion films is superior to that of chromate conversion coating. In addition, the corrosion resistance of conversion film containing cerium compounds on aluminum alloy (Zhang and Zuo, 2008) can also be improved by a post-treatment process. The improvement can account for the fact that post-treatment would eliminate micro cracks on the film surface. As for steel, Yanhua et al. (2013) have studied the combination of rare-earth salts and sodium molybdate to get compounded inhibitors containing rare-earth and Mo for X70 steel. The synergistic effect between sodium molybdate and rare-earth was significant in inhibition corrosion of X70 steel and the best molar ratio of rare-earth ion to molybdenum ion was 1:1.

On the whole, rare-earth conversion films, represented classically by cerium oxide/hydroxide coating, have shown great potential and have been applied in practical metal surface protection. Nevertheless, the relatively weak corrosion resistance of the rare-earth conversion films compared to chromate conversion films restricts their further application, in particular with the applications in marine and industrial environments. Herein, novel and effective treatments for rare-earth conversion films with improved corrosion resistance are still necessary, such as the booming two-step treatments and duplex rare-earth conversion films presented above.

\section{Conductive Polymers}

Conductive polymers represented by polypyrrole (PPy) coatings (Tallman et al., 1999, 2002; Le et al., 2001; Spinks et al., 2002; Shinde et al., 2006) have a history of use in corrosion control in the steel industry. Nowadays, many neoteric promising conductive polymer systems have also been discovered and reported. Nonetheless, the difficulty in processing conductive polymers coupling with all kinds of metals must be overcome in order to develop these polymers. Most of these conductive polymers could only be deposited on some particular metals for lack of fusibility and solubility. Schirmeisen and Beck (1989) investigated the deposition of PPy coating galvanostatically on iron. This electropolymerization process was studied from various aqueous and non-aqueous electrolytes. It was also discovered that PPy films with excellent smooth and adherent properties can only be formed from aqueous nitrate electrolytes. In addition, Ferreira et al. (1996) solved the PPy dissolution problem by metal substrate pretreatment in aqueous $10 \% \mathrm{HNO}_{3}$ solution prior to electrodeposition. After this, many novel pretreatments like nitrate and oxalic to form partial passivation of the steel were established. De Bruyne et al. (1998) adopted an electrodeposition method to achieve an approximate $800 \mathrm{~nm}$ PPy's film on polished steel. The electrolytes are aqueous $0.1 \mathrm{M}$ $\mathrm{H}_{2} \mathrm{C}_{2} \mathrm{O}_{4}$ (oxalate) and $0.5 \mathrm{M} \mathrm{Na}_{2} \mathrm{SO}_{4}$. The advantages of oxalate 
were confirmed, which the iron oxalate intermediate layer was formed before the electrodeposition process. This intermediate layer could be mainly responsible for the strong adhesion between the conducting polymer and steel. In turn, the corrosion resistance of coated PPy samples were improved. "Grainboundaries-pores" model is used for explaining the corrosion protection process. When PPy was coated on the surface of iron, electrons will be in the lowest occupied molecular orbital level. A positively charged metal surface of $\mathrm{Fe}_{3} \mathrm{O}_{4} / \mathrm{Fe}_{2} \mathrm{O}_{3}$ interface is formed. The electron deficiency of $\mathrm{Fe}_{3} \mathrm{O}_{4}$ layer would change the chemical potential, which makes it tougher to oxide $\mathrm{Fe}^{2+}$. Furthermore, the charged layer will inhibit the diffusion process of $\mathrm{Fe}^{2+}$ and $\mathrm{O}^{2-}$, contributing to a slower corrosion.

Apart from applying conductive polymers to steel corrosion protection, conductive polymers are more commonly used for corrosion control of aluminum alloys. In general, most of these conductive polymers involve either polyaniline or polypyrrole. First of all, different polyaniline formations have been discovered for corrosion control of $\mathrm{Al}$ alloys, as an example of deposited on Al 2024-T3 alloy (Tallman et al., 2000) by emeraldine salt (ES), deposited on Al 2024-T3 and Al 3003 alloys by emeraldine base (EB) (Epstein et al., 1999), and deposited on Al 7075 alloy (Racicot et al., 1995, 1997) by molecular complex forms(ES form with polyelectrolyte counterions). These deposited coatings in these above studies were all based on solutions consisting of electroactive conducting polymers (ECP). Racicot et al. $(1995,1997)$ first employed polyaniline to prevent aluminum alloy from corroding. They had successfully adopted a template-oriented synthesis method to synthesize a molecular complex containing polyaniline and polyanions, yielding doublestrand polyanilines. The introduction of polyanions could impart some desirable properties to coated metals, such as improved solubility in common solvents and enhanced adhesion to the substrate or topcoat. Polyanions were typically vinyl copolymers consisting of arboxylic acid and alkyl side groups for better facilitating processing and adhesion. Molecular entanglement and electrostatics could knit the molecular complex together completely and, for this reason, polyanilines can maintain the properties of dopant and conductivity. Samples coated with polyaniline exhibit excellent corrosion resistance through different tests such as potentiodynamic polarization (PP), electrochemical impedance spectroscopy (EIS), and salt-spray test, which could be comparable or better than the Alodine600 treatment (chromate conversion coatings). Epstein et al. (1999) investigated the corrosion protection of pure aluminum and aluminum alloys 3003 and 2024-T3 through the form of EB to deposit polyaniline coating. The EB coating is an oxidized but non-conductive state of polyaniline and could remarkably heighten the rustless property of the coated aluminum and its alloys. Recently, a few researchers have attempted to use polypyrrole for corrosion protection of aluminum alloy and achieved some unexpected results. Tallman et al. (2002) discovered the pitting behavior of polypyrrole-based alloys could be more effectively suppressed than that of polyanilinebased alloys. In addition, He's group discussed the interactions between poly(3-octylpyrrole) (POP) and Al 2024-T3 alloy by scanning vibrating electrode technique (SVET). The current flow of POP-coated alloys shows a significant delay when compared to epoxy-coated ones. Also, only reduction current was detected within the defect area of POP-coated alloy while oxidation current and reduction current were observed within the defect area of epoxy-coated ones. In addition, in order to get broader applications of POP, Gelling et al. (2001) studied long-term immersion of a composite coating system consisting of a POP pretreatment layer and a polyurethane topcoat, which was applied on aluminum 2024-T3 alloy. This composite coating could maintain high impedance values and shows no evidence of failure after a 2.5 years immersion experiment, which revealed excellent long-lasting anticorrosion performance of the as-prepared samples. More recently, Naoi et al. (1995) have used surfactant sulfonates to promote the growth of polypyrrole films. The ointment is that the corrosion protection of this film is not assessed.

Nevertheless, developing new conductive polymers (CPs) that exhibit a better anticorrosion performance when faced with various kinds of environments remains a challenge. Currently, the commonly used methods to achieve this goal can be divided into three categories according to different mechanisms. The specific classifications are as follows: (1) copolymerization CPs, (2) nanostructured CPs, (3) composites of CPs. For example, the corrosion resistance of mild steel could be elevated through the use of poly ( $N$-methyl pyrrole) and/or its copolymer (Weidlich et al., 2005). Furthermore, pyrrole was also copolymerized with ter-polymerpoly (pyrrole-co-o-anisidine-cotoluidine), improving the water resistance of the CPs (Yalçınkaya et al., 2010). Yao et al. (2008) synthesized polyaniline nanofibers onto carbon steel by interfacial polymerization and compared the corrosion behavior with conventional polyaniline-covered carbon steel in sodium chloride solutions. The corrosion current of polyaniline nanofibers coating was lower than that of conventional polyaniline coating to carbon steel, which was owing to the formation of denser coating layer induced by nanofibers. Yang et al. (2010) successfully employed three polymerization methods to synthesize polyaniline nanofibers in sulfuric acid aqueous solution. They discovered that an optimal synthetic method was direct mixed reaction. Compared with the other two polymerization methods (conventional polymerization and interfacial polymerization), films that get through direct mixed reaction exhibit more homogeneous morphology and improved corrosion resistance. Last but not least, composite materials can couple the characteristics of CPs and multifarious functional materials, which would impart the coatings better corrosion resistance. Different kinds of metals, metal oxide particles, non-metallic particles, and nanomaterials can be encapsulated into polyaniline coatings. The introduction of zinc nanoparticles between polyaniline coatings could achieve improvements in conductivity and anticorrosion compared to zinc micro-sized particles (Olad and Rasouli, 2010). Moreover, nanoSiO $\mathrm{S}_{2}$ is one of the most promising nanoparticles applied into anticorrosive coatings. $\mathrm{NanoSiO}_{2}$-polyaniline composites deposited on mild steel show enhanced protective performance in comparison to polyaniline alone. The synergistic effect of nanoSiO 2 hydrophobicity ability and polyaniline redox catalytic property would be responsible for the improvement 
of anticorrosion (Weng et al., 2012). Generally speaking, the CPs should be given much more attention in the aspect of practical corrosion protection application, since they own excellent chemical compatibility that can be applied into different forms, and some of them could exhibit a highly stable corrosion resistance.

\section{Self-Assembled Films}

Self-assembled films have also attracted much attention because of their adaptability for coatings and corrosion protection applications, despite the self-assembled films having some shortcomings concerning the sharp degradation of corrosion resistance of self-assembled monolayer (SAM), as their thermal stability is relatively poor. However, the properties of ease of fabrication, characterization, and manipulation make sure that SAM remains popular among coating fields. For example, SAM of alkanethiols, represented by $\mathrm{C}_{\mathrm{n}} \mathrm{H}_{2 \mathrm{n}+1} \mathrm{SH}(n=6 \sim 18)$, are good selections for copper corrosion protection applications because they can adsorb on the surface of copper and act as a dense barrier coating (Yamamoto et al., 1993). Hydrolysis and condensation reactions are expected to explain the corrosion protection process. Cross-linked alkanethiol layer is directly chemisorbed on the metal surface and co-polymerized with hydrolyzed silanes, which could make the surface more hydrophobic and improve the corrosion resistance ability. In order to overcome the potential shortcomings, such as relatively insufficiently high protection abilities of the SAM in some corrosive medium solutions, modifications of SAM and some novel types of SAM with improved corrosion resistance have been discovered for the purpose of their potential applications in corrosion protection.

Shahrabi's group reported a series of SAM derived from Schiff bases and their modifications as new candidates for application in $\mathrm{Cu}$ corrosion protection (Ehteshamzade et al., 2006). Two ligands Schiff bases, $N, N^{\prime}$-ortho-phenylen-bis (salicylidenimine) (S-o-ph-S) and $N, N^{\prime}$-ethylen-bis (salicylidenimine) (S-E-S) were chosen to be chemisorbed on a copper surface to achieve SAM. The corrosion inhibition behavior was researched by EIS and Tafel polarization curve. Electrochemical results proved that the corrosion inhibition efficiency of SAM of S-o-ph-S is higher than that of S-E-S. Thermodynamics calculations of S-o-ph-S and S-E-S certified that S-o-ph-S would display more negative adsorption free energy and a larger adsorption constant compared to S-E-S, which could further confirm the electrochemical results. They also attempted to modify SAM of Schiff bases with two kinds of alkanethiols: 1-dodecanethiol and propanethiol. Two kinds of alkanethiols strengthened the corrosion inhibition efficiency of prepared SAM based on Schiff bases, owing to the more densely packed formation of the coatings accompanied by much fewer defects on the surface. Unfortunately, the above-mentioned effective inhibitors are toxic, which is harmful to both the environment and human body. Therefore, environmentally friendly inhibitors gradually have become a hot issue in recent years. The representative non-toxic inhibitor is imidazole, wherein two nitrogen atoms exist in the heterocyclic (Zhang et al., 2009). Apart from protecting copper, Hackerman et al. investigated the corrosion inhibitive properties of heterocyclic diazoles to prevent iron from corrosion in acidic media (Babiæ-Samardžija et al., 2005). They drew a conclusion that two nitrogen atoms in different positions in heterocycle of imidazole could have a more striking impact on corrosion inhibition of prepared coatings. The corrosion inhibition behavior of imidazole derivatives were superior to that of pyrazole derivatives. The differences between pyrazole and imidazole are that two nitrogen of pyrazole are contiguous in heterocycle while there is a carbon atom between two nitrogen atoms of imidazole. The substituent on the carbon atom will have a positive effect between the SAM and iron, leading to the improvement of corrosion inhibition. Recently, (Zhang et al., 2009) Chen's group applied imidazole and its derivatives that attached either with distinct lengths of alkane chains or with disparate functional groups to investigate the defending consequences for coated iron in acidic solution. The names and abbreviations are, respectively imidazole (IMZ), 1-benzyl-1H-imidazole (BIMZ), (E)-3-(4-( $1 \mathrm{H}$-imidazol-1yl)methyl)phenyl)acrylic acid (IMMP), 1-buty1-1H-imidazole (BTIM), 1-tosyl-1H-imidazole (TSIM) and (E)-methyl 3(4-((1H-imidazol-1-yl)methyl)phenyl)acrylate (MIMMP). Corrosion inhibition behavior of these six SAM were studied by modifications of the immersion time, assembling temperature, and the concentration of assembling solution. Electrochemical tests certificated that the series of imidazole compounds were suitable corrosion inhibitors for acid iron corrosion and that MIMMP is the best inhibitor among them. But there was no specific mechanism mentioned as to why MIMMP had the optimal corrosion inhibition in that paper.

As a short conclusion, self-assembled films, especially imidazole and its derivatives, could be a potential option for corrosion protection of steel in practice if the thermal stability can be resolved or further enhanced. Relatively easy synthesis methods and various modifications, combined with suitable functional groups, make sure that this series of selfassembled films attracts much attention with regard to their future applications.

\section{THE LIFE EVALUATION OF AFOREMENTIONED COATING SYSTEMS}

Hot-dip galvanized steel based on aforementioned coating systems is of great importance for various applications; consequently, these novel coating systems with optimized or anticipated properties are incessantly researched by materials or chemistry researchers. At the same time, the life evaluation of these duplex coating systems is quite tough but essential and also attracts the attention of a large number of researchers. The purpose of life evaluation of those coating systems for HDGS is to quantitatively assess the corrosion resistance of coatings and to determine whether the coating system fails to avoid greater losses, such as corrosion failure. Up to now, there has been no unified definition of the lifetime of duplex coating systems. There are three main opinions to judge the coating systems to reach its service life,: (1) any rust appeared on the surface of coated metal, (2) perforation of coated metal, (3) rust area of the coated metal reaching a predetermined value (Zhen, 2005). For the 
shortcoming of long field test cycle, indoor corrosion acceleration tests can effectively evaluate the service life of the coatings in a short time under certain environments. Therefore, a consensus has been reached that the life prediction of coated metals is usually obtained by summarizing the correlation of results of indoor corrosion acceleration tests and field tests among scientific researchers. In other words, it is vital to grasp the corrosion mechanism of the coated metal under the circumstance of indoor corrosion acceleration tests and put forward appropriate evaluation methods based on the corrosion mechanism. As to metal coated with single coating (metallic coatings or organic coatings), the accelerated corrosion evaluation method of metal has been proposed and recognized (such as various standards) and some of these standards also provide quantitative assessment criteria. For metallic coatings, galvanizing coating would be taken as an example. Service lifetime of galvanizing coating is traditionally referred to the time for the red rust area to reach $5 \%$ of the whole area of galvanizing layer in the situation of accelerated test. Zhang and $\mathrm{Xu}$ (2007) covered the correlation between accelerated corrosion tests and actual corrosion conditions, concentrating on the corrosion rate ratio of steel to zinc. "Zinc coating life predictor" was also invented based on numerous statistics on corrosion of steel and zinc. Fujita and Mizuno (2007) researched the perforation corrosion of zinc or steel coated with zinc alloy and evaluated the lifetime of various coated steel sheets based on different kinds of accelerated corrosion tests. They divided the perforation corrosion procedure into four periods. Stage 1: the whole surface of substrate steel is covered with zinc coating and no other than the zinc coating is corroded $\left(\tau_{1}\right)$. Stage 2: zinc coating is just lost fractionally, and this film continues to be corroded sacrificially to protect steel $\left(\tau_{2}\right)$. Stage 3: zinc coating is entirely lost and the steel starts to be corroded. Meanwhile, zinc corrosion products can inhibit the overall corrosion rate of galvanized steel $\left(\tau_{3}\right)$. Stage 4 : zinc coating completely loses its protective effect and steel is corroded quickly $\left(\tau_{4}\right)$. The schematic diagram of corrosion process of galvanized steel was shown in Figure 6. So as to illuminate the connection between different accelerated corrosion tests and actual corrosion, they took (Zhang and $\mathrm{Xu}, 2007$ ) as references to propose a concept named Perforation Corrosion Index (PCI) for the evaluation of the perforation corrosion of galvanized steel. Specific formula was as follows:

$$
\mathrm{PCI}=V_{\text {Steel }} / V_{\text {Zinc }}
$$

Where, $V_{\text {Zinc }}$ and $V_{\text {Steel }}$ were defined, respectively as follows:

$$
\begin{gathered}
V_{\text {Zinc }}=d_{\text {coating }} /\left(\tau_{1}+\tau_{2}+\tau_{3}\right) \\
V_{\text {Steel }}=d_{\text {Steel }} / \tau_{4}
\end{gathered}
$$

$d$ coating and $d_{\text {steel }}$ were, respectively the thickness of zinc coating and steel.

Through this formula, the PCI of accelerated corrosion tests would coincide with the actual corrosion in Detroit, proving the feasibility of PCI. Regrettably, it is not universal for various metals and different corrosion conditions.

As for the lifetime prediction of organic coatings, Mayne combined the Fick diffusion law with electrochemistry of coated

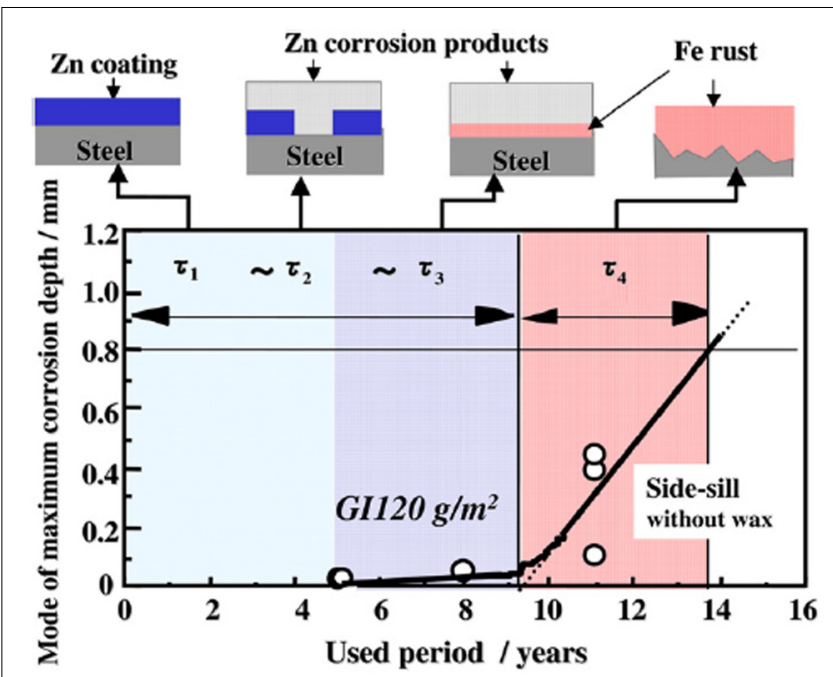

FIGURE 6 | The schematic diagram of corrosion process of galvanized steel (Fujita and Mizuno, 2007).

steel plate to propose a life prediction formula of organic coating based on the "control theory of coating polarization resistance" (Maitland, 1962). The formula was as follows:

$$
L=l^{2} /(6 D)+\phi\left(p_{s} \sigma_{n}\right)
$$

Where, $L$ and $l$ were, respectively the lifetime of coating and the depth of coating, $D$ represented the diffusion coefficient of coating ions, $\phi$ was a constant, $p_{s}$ and $\sigma_{\mathrm{n}}$, respectively referred to the adhesion of coating and applied pressure on the surface of steel. Chuang (1997) established a mathematical model on the basis of coating bubbling, where the bubbling growth rate $V$ is regarded as a function of torque, material properties and temperature. Finally, the life of the coating system was obtained:

$$
V_{\min }=1.83\left(\sigma_{f} / W\right)^{5 / 4}\left(D_{b} \delta_{b} \Omega / k T\right)\left[E h^{3} / 12\left(1-v^{2}\right)\right]^{1 / 4}
$$

Where, $\sigma_{f}$ was the layered stress, $W$ was the cross-sectional area of the coating, $D_{b} \delta_{b}$ was interfacial diffusivity, $\Omega, k$, and $T$ were constant, $\nu$ and $E$ were, respectively PoissoN's ratio and elastic modulus of coatings under wetting condition, $h$ was the total thickness of coatings. Although the formula of organic coating life prediction was established, its accuracy was questionable. Due to the diversity of coatings and difference of corrosion environment, no general formula has been found that can accurately predict the service life of coatings so far.

Apart from the above-mentioned life prediction formula, EIS technology gradually becomes a powerful tool to predict organic coating life. EIS affords an in situ non-destructive measurement of the corrosion behavior of protective coating, which can reflect information about corrosion reaction, mass transfer, and charge transfer (Grundmeier et al., 2000; Vogelsang and Strunz, 2001). This technique is strengthened by the current response of the small sinusoidal perturbation of electrode potential in variations with perturbation frequency. Equivalent circuit methods are commonly utilized to analyze and interpret the EIS data. The 
equivalent circuit normally consists of electrical elements that simulate the electrode/solution interface. Resistance $(R)$ and capacitors $(C)$ are the most typically used electrical components. Under some circumstances, constant phase elements (CPE) instead of capacitors $(C)$ were introduced to achieve satisfactory fittings. Warburg impedance is appropriate for diffusion process. Adopted equivalent circuit models should consider the following principles: (1) Electrical components used in equivalent circuits must have clear physical meanings. That is, they must correspond to physical properties of the system that can produce such electrical responses; (2) Equivalent circuits must generate spectra and parameters in the circuits have appropriate values. Although spectra are different from experimental spectra, acceptable errors are allowed; and (3) The proposed equivalent circuits should be as simple as possible. Cao and Zhang (2002) proposed six equivalent circuit models according to the characteristics of impedance spectra of organic coating systems in different immersion periods. For a wide variety of organic coating systems, three basic physical processes are common: (1) Dielectric relaxation process. This process is represented by coating capacitance $C_{\mathrm{c}}$, which generally occurs in the high frequency region of impedance spectra; (2) Charge transfer process at metal/solution interface. This process is represented by charge transfer resistance $R_{\mathrm{ct}}$ and double layer capacitance $C_{\mathrm{dl}}$, which occurs after the corrosive solution reaches the organic coating/metal interface; (3) Diffusion process. This process usually exists in the coating pores and occurs in the low frequency part of impedance spectra (Strunz, 2000).

Sekine et al. (1992) discovered a linear relationship between $f_{\theta \max }$ and $R_{\mathrm{c}}$, in which $R_{\mathrm{c}}$ is the coating resistance and $f_{\theta \max }$ refers to the frequency with which phase angle is at maximum. The relationship may work as a standard to judge the corrosion resistance of organic coatings, whereas $f_{\theta \max }$ can be easily measured. Mahdavian and Attar (2006) analyzed and compared the differences in anti-corrosion performance of zinc phosphate coatings and zinc chromate coatings through the phase angle at $10 \mathrm{kHz}$. Haruyama and Sudo (1993) put forward a novel concept: breakpoint frequency $f_{b}$, a frequency where firstly the phase angle descends to $45^{\circ}$, and discovered a better correlation between delaminated areas of organic coating on the metal and breakpoint frequency. Mansfeld and Tsai (1991) put forward two new parameters: $\theta_{\min }$ and $\mathrm{f}_{\theta \min }$, which, respectively represent the minimum phase angle and corresponding frequency. It can be indicated that the $\theta_{\min }$ and the proportion of $\mathrm{f}_{b} / \mathrm{f}_{\theta \text { min }}$ were all up to the stripping area between the as-prepared organic coatings and substrate metal. The above-mentioned methods all analyze high frequency regions of the impedance spectrum to predict the performance of organic coatings, which could avoid the measurements in low frequency regions of the impedance spectrum and develop fast lifetime evaluation for organic coatings. In addition, Zuo et al. (2008) found that the phase angle and coating resistance in the middle frequency domain from Bode plots show analogously descending tendencies. The changes of phase-angle at $10 \mathrm{~Hz}$ varying with the soaking time in $3.5 \% \mathrm{NaCl}$ solution was in accordance with the variation of coating resistance, which could reflect the corrosion resistance of organic coating qualitatively. In the event that the phase angle
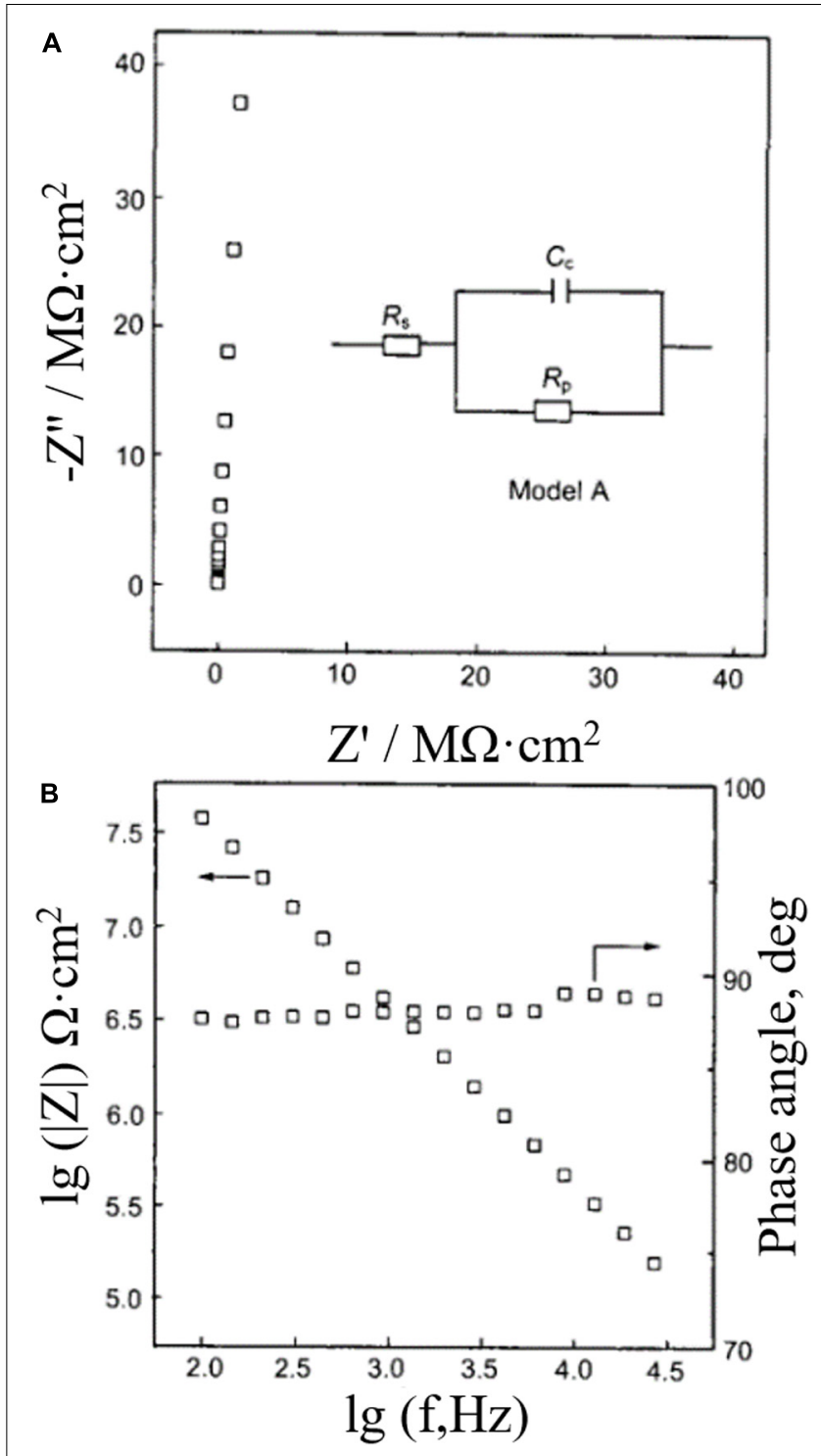

FIGURE 7 | (A) Impedance complex plane, circuit model, and (B) bode diagram of epoxy coated LY12 aluminum alloy immersed in $3.5 \% \mathrm{NaCl}$ solution for 12 min (Hu et al., 2003).

at $10 \mathrm{~Hz}$ decreased into a range of $20 \sim 40^{\circ}$, the electrolytes would thoroughly permeate into the organic coatings and electrochemical reactions underneath those protected coatings began to react quickly. Therefore, the phase angle at the frequency of $10 \mathrm{~Hz}$ could be applied for a quick evaluation of organic coating performance.

More recently, $\mathrm{Hu}$ et al. have studied the electrochemical impedance spectra of LY12 aluminum alloy/epoxy coating at distinct immersion stages in $3.5 \% \mathrm{NaCl}$ solution (Hu et al., 2003; Zhang et al., 2004). They thought that the aging failure of organic coatings could be divided into four stages.

Stage 1: At the initial time of immersion, only one time constant appears on the electrochemical impedance spectrum, which shows an equivalent circuit of coating pore resistance $\left(R_{\mathrm{p}}\right)$ 
in parallel with coating capacitor $\left(C_{\mathrm{c}}\right)$, in which $R_{\mathrm{s}}$ is solution resistance. Figure 7 shows the equivalent mode A, Nyquist plots and Bode plots of the composite electrode immersed in 3.5\% $\mathrm{NaCl}$ solution for $12 \mathrm{~min}$.

Stage 2: When water, $\mathrm{O}_{2}$, and other substances with larger diffusion coefficients pass through the coating and reach the substrate, the electrochemical interface of metal/electrolyte solution is established, and electrochemical reaction impedance start to appear. The equivalent circuit of this stage is shown in model B in Figure 8. The high frequency section of the impedance spectrum corresponds to the coating itself $\left(C_{\mathrm{c}} R_{\mathrm{p}}\right)$, and low frequency regions of that corresponds to electrochemical reaction impedance $\left(C_{\mathrm{dl}} R_{\mathrm{ct}}\right)$ at the metal/solution interface,
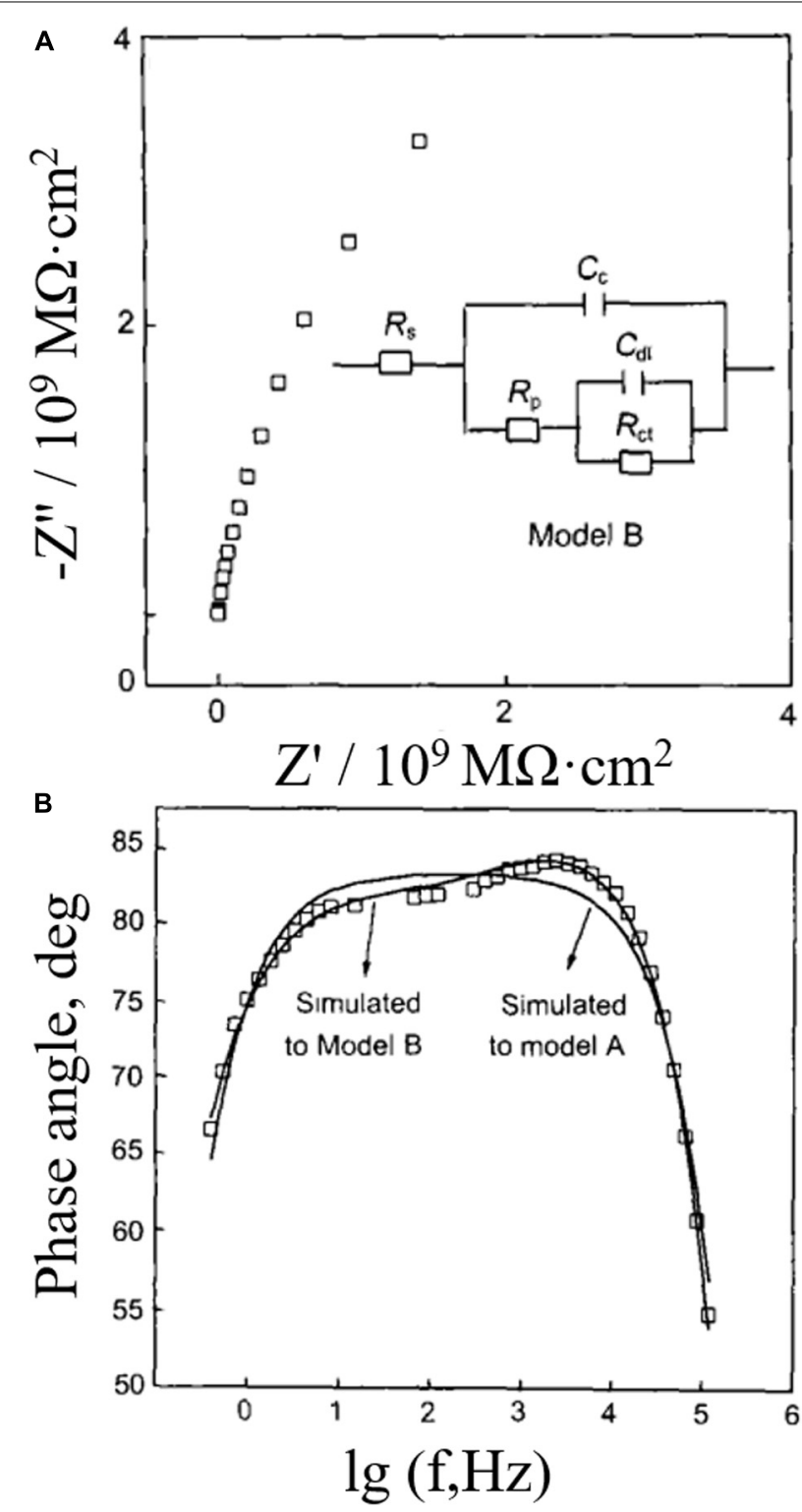

FIGURE 8 | (A) Impedance complex plane, circuit model, and (B) phase angle diagram of coated metal immersed in pure water for $3 \mathrm{~h}$ (Hu et al., 2003).

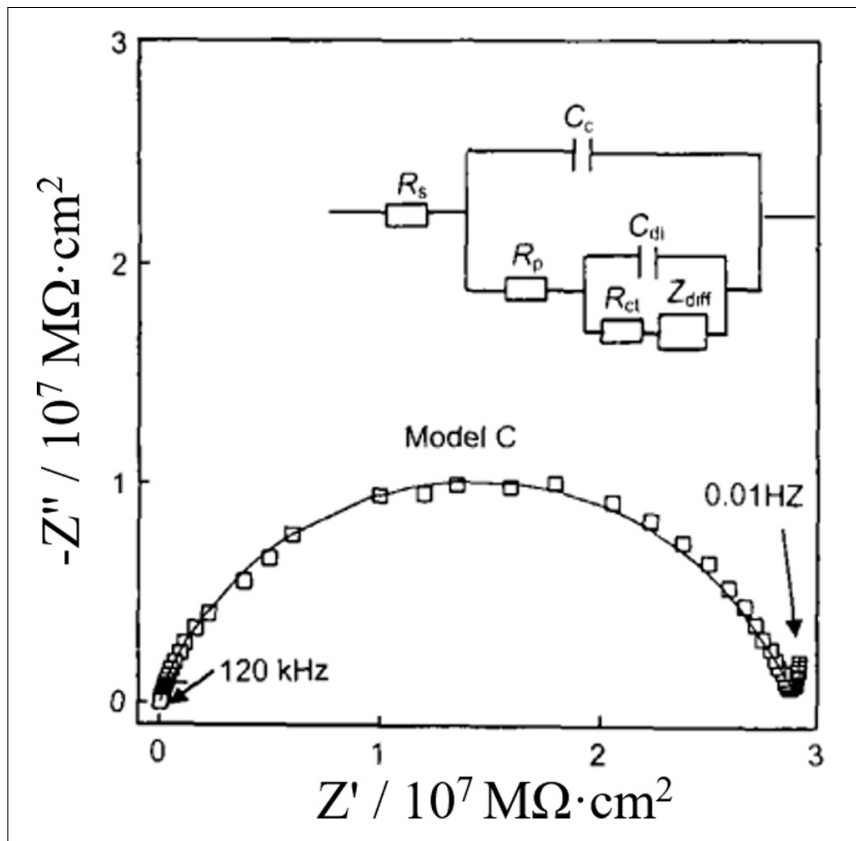

FIGURE 9 | Impedance complex plane and circuit model of coated metal immersed in pure water for $48 \mathrm{~h}$ (Hu et al., 2003).

in which $C_{\mathrm{dl}}$ refers to double-layer capacitance and $R_{\mathrm{ct}}$ is electrochemical reaction resistance.

Stage 3: Affected by the barrier of coating, the transmission of corrosion products on the metal surface is inhibited, resulting in the emergence of diffusion impedance $Z_{\text {diff }}$. The equivalent circuit of this stage is shown in model $\mathrm{C}$ in Figure 9. In addition, Figure 9 also shows the impedance complex plan of the electrode immersed in pure water for $48 \mathrm{~h}$.

Stage 4: When the corrosive ions with small diffusion coefficients such as $\mathrm{Cl}^{-}$ion reach the metal/coating interface through the coating, chemical reactions between $\mathrm{Cl}^{-}$and the soluble corrosion products at the interface appear to generate salt film. Faraday impedance is the sum of salt film impedance $\left(R_{s f} C_{s f}\right)$ and electrochemical dissolution impedance $\left(R_{o f} C_{o f}\right)$ of the alloy. The equivalent circuit of this stage is shown in model $\mathrm{D}$ in Figure 10. Figure 10 illustrates the appearance of double capacitance arcs by taking the impedance complex plan of coated metal immersed in $3.5 \% \mathrm{NaCl}$ solution for $388 \mathrm{~h}$ as an example. It is considered that the high frequency capacitive reactance arc corresponds to the characteristic impedance of film forming reaction involving $\mathrm{Cl}^{-}$ions on aluminum substrate surface, while the low frequency capacitive reactance arc corresponds to the anodic electrochemical reaction impedance of the surface of aluminum substrate.

Speaking of duplex coatings, so far there have not been any accelerated corrosion evaluation standard for composite coating systems, such as carbon steel coated with firstly a galvanizing coating and then an organic coating. It is inappropriate to evaluate the corrosion resistance of composite coatings by simply applying the evaluation criteria of single coatings. For example, some researchers (Bacon et al., 1948) discovered that when the 


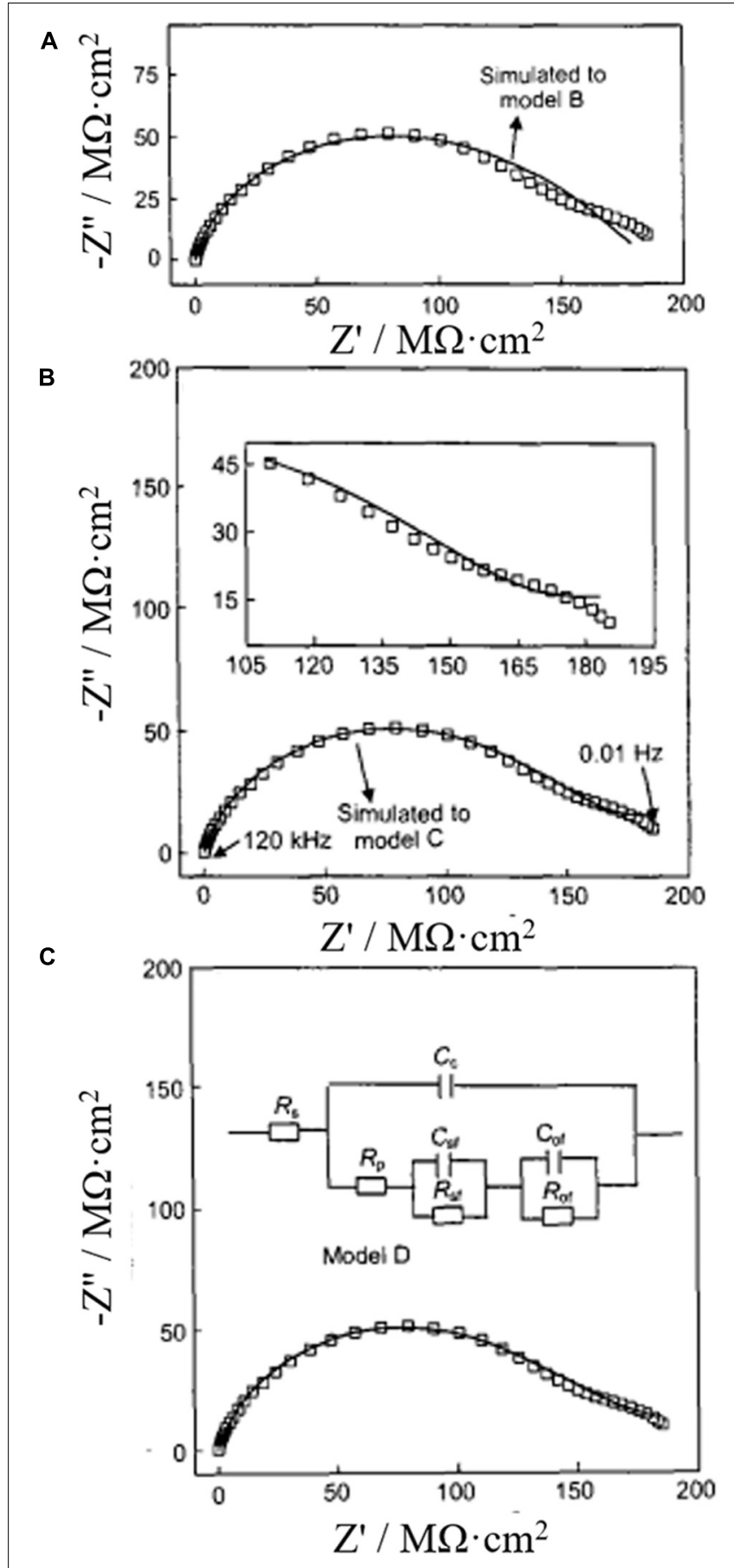

FIGURE 10 | (A-C) Impedance complex plane and circuit model of coated metal immersed in $3.5 \% \mathrm{NaCl}$ solution for $388 \mathrm{~h}$ (Hu et al., 2003).

electrochemical impedance modulus of organic coatings reached $10^{8} \Omega \mathrm{cm}^{2}$ or above, organic coatings had better corrosion resistance. While the electrochemical impedance modulus of organic coatings was less than $10^{8} \Omega \cdot \mathrm{cm}^{2}$, their anticorrosion performance was relatively poor. Even when the electrochemical impedance modulus descended to $10^{6} \Omega \cdot \mathrm{cm}^{2}$, the coatings could be considered to have failed completely. But for HDGS, its impedance modulus is usually no more than $10^{6} \Omega \cdot \mathrm{cm}^{2}$. It cannot be indicated that the zinc coating has failed by impedance modulus alone and, in fact, the zinc coating may be intact. Therefore, this evaluation standard does not apply to metallic coating. That is, the evaluation standard for single coating is not suitable for composite coating.

However, by summarizing the above research on the lifetime evaluation of metal coatings and organic coatings, it was found that the failure process of two distinct kinds of coatings studied above are similar to each other to some extent, and both of their failure processes can be regarded as going through four stages. Based on these, we propose a novel method for evaluating the accelerated lifetime of composite coating system. There are synergies among the overall lifetime of the composite coatings $\left(L_{\mathcal{c}}\right)$ (Dallin et al., 2018) and the lifetime of organic coating $\left(L_{f}\right)$ and the lifetime of zinc coating $\left(L_{z}\right)$ for composite coating system: $L_{\mathrm{c}}=\mathrm{k}\left(L_{f}+L_{z}\right), \mathrm{k}=1.5 \sim 2.3$. Therefore, the research of composite coating lifetime can be divided into two aspects: organic coating lifetime and galvanizing coating lifetime. For organic coatings, we can evaluate the failure process by the four stages proposed by Hu's group and the appearance of double capacitance arcs marks the final lifetime of the organic coating. For galvanizing coatings, we not only need to judge the four stages of corrosion process, but also need to combine the potential reversal of steel and zinc to comprehensively judge the life of the galvanized layer. Due to the sacrificial anode protection ability of the galvanizing layer, even when the corrosive substances such as $\mathrm{Cl}^{-}$pass through the galvanizing layer and reach the substrate, the carbon steel may not immediately corrode, which results in the time that the corrosive ions such as $\mathrm{Cl}^{-}$reach the metal/coating interface not necessarily being the same as the time for the protection life of galvanizing coating. When the corrosion rate of galvanized steel increases rapidly, the open circuit potential of galvanized steel should reverse. While zinc loses the anodic protection of steel and the carbon steel substrate starts to corrode quickly, the corrosion rate of galvanized steel should increase rapidly, and the open circuit potential of galvanized steel will reverse. Specific experimental verification is still in progress and ready to be published.

\section{CONCLUSION AND FUTURE WORK}

Novel and high-efficiency corrosion resistant coating systems for HDGS are highly significant for their wide applications in things such as high-speed rail overhead line parts. They are important to, for example, galvanizing process control, paint coatings, and electrochemical protection; they ensure that the global HDGS field is at a leading position by applying various coating systems for their superior corrosion resistance. For the moment, novel coating systems still need to acquire corrosion resistance coatings with better adhesion property to the substrates on the basis of the types of HDGS, and need to enhance the corrosion resistance efficacy for the purpose of prolonging the service life of devices or fulfilling the applications of HDGS under 
more severe natural environments. Hence, plenty of novel and efficient coating systems are invented and reported as a brief summary in this light. Furthermore, valid tactics for the discovery of new coating systems, such as silane films, rare-earth conversion films, conductive polymers, and self-assembled films, have been illustrated by the latest reported literature.

The future developments of coating systems for HDGS would affect a number of fields. Firstly, the modifications of the present coating systems would be affected through, for example, the structural modification of silane films and composition optimization of rare-earth conversion films. Also affected would be the discovery of novel coating systems. To cope with the worsening environment, new-emerging coating systems with better improved corrosion resistance should be necessary for the future applications of HDGS. Thirdly, methodology research for the evaluation of these aforementioned coating systems would be influenced by any developments in coating systems for HDGS. Due to the lack of unified lifetime evaluation methods for these composite coating systems, it is desiderate to establish reasonable lifetime evaluation criteria. The establishment of evaluation

\section{REFERENCES}

Aldykewicz, A., Isaacs, H., and Davenport, A. (1995). The investigation of cerium as a cathodic inhibitor for aluminum-copper alloys. J. Electrochem. Soc. 142, 3342-3350. doi: 10.1002/chin.199604011

Al-Mehthel, M., Al-Dulaijan, S., Al-Idi, S. H., Shameem, M., Ali, M., and Maslehuddin, M. (2009). Performance of generic and proprietary corrosion inhibitors in chloride-contaminated silica fume cement concrete. Construct. Build. Mater. 23, 1768-1774. doi: 10.1016/j.conbuildmat.2008.10.010

Aramaki, K. (2001a). The inhibition effects of cation inhibitors on corrosion of zinc in aerated 0.5 M NaCl. Corros. Sci. 43, 1573-1588. doi: 10.1016/S0010-938X(00) 00144-X

Aramaki, K. (2001b). Treatment of zinc surface with cerium (III) nitrate to prevent zinc corrosion in aerated $0.5 \mathrm{M} \mathrm{NaCl}$. Corros. Sci. 43, 2201-2215. doi: 10.1016/ S0010-938X(00)00189-X

Aramaki, K. (2005). A self-healing protective film prepared on zinc by treatment in a $\mathrm{Ce}$ (NO3) 3 solution and modification with Ce (NO3) 3. Corros. Sci. 47, 1285-1298. doi: 10.1016/j.corsci.2004.05.022

Asgari, H., Toroghinejad, M., and Golozar, M. (2007). On texture, corrosion resistance and morphology of hot-dip galvanized zinc coatings. Appl. Surface Sci. 253, 6769-6777. doi: 10.1016/j.apsusc.2007.01.093

Babiæ-Samardžija, K., Lupu, C., Hackerman, N., Barron, A. R., and Luttge, A. (2005). Inhibitive properties and surface morphology of a group of heterocyclic diazoles as inhibitors for acidic iron corrosion. Langmuir 21, 12187-12196. doi: 10.1021/la0517661

Bacon, R. C., Smith, J. J., and Rugg, F. M. (1948). Electrolytic resistance in evaluating protective merit of coatings on metals. Ind. Eng. Chem. 40, 161-167. doi: 10.1021/ie50457a041

Bera, S., Rout, T., Udayabhanu, G., and Narayan, R. (2016). Water-based \& eco-friendly epoxy-silane hybrid coating for enhanced corrosion protection \& adhesion on galvanized steel. Prog. Org. Coat. 101, 24-44. doi: 10.1016/j. porgcoat.2016.07.010

Brachetti-Sibaja, S., Dominguez-Crespo, M. A., Torres-Huerta, A. M., De la CruzHernández, W., and Onofre-Bustamante, E. (2011). Bath conditions role in promoting corrosion protection on aluminum alloy using rare earth conversion coatings. J. Electrochem. Soc. 159, C40-C57. doi: 10.1149/2.035201jes

Breval, E., and Rachlitz, M. (1988). Hot-dip galvanized steel: surface structures and adhesion of paints. J. Mater. Sci. 23, 1835-1840. doi: 10.1007/BF01115729

Cabral, A., Trabelsi, W., Serra, R., Montemor, M., Zheludkevich, M., and Ferreira, M. (2006). The corrosion resistance of hot dip galvanised steel and AA2024-T3 pre-treated with bis-[triethoxysilylpropyl] tetrasulfide solutions doped with Ce (NO3) 3. Corros. Sci. 48, 3740-3758. doi: 10.1016/j.corsci.2006.01.010 methods will have a huge positive impact on production and life, asit will allow us to judge whether the coating systems will lose protection functioning to avoid greater losses. Therefore, it is essential to comprehensively understand the experimentally and theoretically intrinsic properties of the corrosion process for the HDGS composite coating systems in relation to the life evaluation of these coating systems and the design of preferable coating systems for HDGS.

\section{AUTHOR CONTRIBUTIONS}

This review is mainly accomplished by ZY under the guidances of $\mathrm{HM}$ and $\mathrm{JH}$.

\section{FUNDING}

The present study was financially supported by National Key R\&D Program of China (2017YFB1200800).

Cachet, C., Ganne, F., Joiret, S., Maurin, G., Petitjean, J., Vivier, V., et al. (2002) EIS investigation of zinc dissolution in aerated sulphate medium. Part II: zinc coatings. Electrochim. Acta 47, 3409-3422. doi: 10.1016/S0013-4686(02)002 77-3

Cachet, C., Ganne, F., Maurin, G., Petitjean, J., Vivier, V., and Wiart, R. (2001). EIS investigation of zinc dissolution in aerated sulfate medium. Part I: bulk zinc. Electrochim. Acta 47, 509-518. doi: 10.1016/S0013-4686(01)00740-X

Cao, C., and Zhang, J. (2002). Introduction to Electrochemical Impedance Spectroscopy. New York, NY: The Science Publishing Company.

Capelossi, V. R., and Aoki, I. V. (2013). Influence of sonication on anticorrosion properties of a sulfursilane film dopped with Ce (IV) on galvannealed steel. Prog. Org. Coat. 76, 812-820. doi: 10.1016/j.porgcoat.2013.01.012

Chang, J.-K., Lin, C.-S., Cheng, W.-J., Lo, I.-H., and Wang, W.-R. (2019). Oxidation resistant silane coating for hot-dip galvanized hot stamping steel. Corros. Sci. 164:108307. doi: 10.1016/j.corsci.2019.108307

Chen, Y., Chung, S., and Shih, H. (2006). Studies on the initial stages of zinc atmospheric corrosion in the presence of chloride. Corros. Sci. 48, 3547-3564. doi: 10.1016/j.corsci.2005.12.007

Chen, Z., Kennon, N., See, J. B., and Barter, M. (1992). Technigalva and other developments in batch hot-dip galvanizing. JoM 44, 22-26. doi: 10.1007/ BF03222746

Chuang, T. (1997). "A non-osmotic blister growth model in coating systems," in Damage and Failure of Interfaces. 1st International Conference. Proceedings., (Amsterdam: AA Balkema Publishers), 22-24.

Cole, I., Muster, T., Lau, D., Wright, N., and Azmat, N. S. (2010). Products formed during the interaction of seawater droplets with zinc surfaces II. Results from short exposures. . J. Electrochem. Soc. 157, C213-C222. doi: 10.1149/1.3391383

Culcasi, J. D., Elsner, C. I., and Di Sarli, A. R. (2009). Effect of zinc crystals size on galvanized steel deformation and electrochemical behavior. Mater. Res. 12, 273-279. doi: 10.1590/S1516-14392009000300005

Cuttone, L. D. C., Cristini, S., Trueba, M., and Trasatti, S. (2016). Electrochemical investigation of polyaniline blends on galvanized steel. Prog. Org. Coat. 96, 65-79. doi: 10.1016/j.porgcoat.2016.02.011

Dafydd, H., Worsley, D., and McMurray, H. (2005). The kinetics and mechanism of cathodic oxygen reduction on zinc and zinc-aluminium alloy galvanized coatings. Corros. Sci. 47, 3006-3018. doi: 10.1016/j.corsci.2005.05.036

Dallin, G., Goodwin, F. E., and Pole, S. (2018). "Duplex zinc coatings for corrosion protection of steel structures," in Transportation Research Board 97th Annual Meeting, Washington, DC.

Dan, Z., Jie, S., Zhang, L., Yong, T., and Ji, L. (2010). Corrosion behavior of rare earth cerium based conversion coating on aluminum alloy. J. Rare Earths 28, 371-374. doi: 10.1016/S1002-0721(10)60338-9 
De Bruyne, A., Delplancke, J.-L., and Winand, R. (1998). Comparison between polypyrrole films obtained on mild steel by electropolymerization from oxalic acid and sodium sulphate aqueous solutions. Surface Coat. Technol. 99, 118124. doi: 10.1016/s0257-8972(97)00417-9

Deshpande, P., Vagge, S., Jagtap, S., Khiarnar, R., Kelkar, S., and More, M. (2012). Conducting polyanilline based paints on hot dip galvanized low carbon steel for corrosion protection. Bulgarian Chem. Commun. 44, 318-323.

Di Sarli, A. R., Elsner, C. I., and Tomachuk, C. (2014). Characterization and corrosion resistence of galvanized steel//passivation compositive/polyuethane paint systems. Br. J. Appl. Sci. Technol. 4, 853-878. doi: 10.9734/BJAST/2014/ 6813

Ehteshamzade, M., Shahrabi, T., and Hosseini, M. (2006). Inhibition of copper corrosion by self-assembled films of new Schiff bases and their modification with alkanethiols in aqueous medium. Appl. Surface Sci. 252, 2949-2959. doi: 10.1016/j.apsusc.2005.05.003

El-Sayed, A.-R., Harm, U., Mangold, K.-M., and Fürbeth, W. (2012). Protection of galvanized steel from corrosion in $\mathrm{NaCl}$ solution by coverage with phytic acid SAM modified with some cations and thiols. Corros. Sci. 55, 339-350. doi: 10.1016/j.corsci.2011.10.036

El-Shazly, A., and Al-Turaif, H. (2011). "Improvement of the corrosion resistance for the galvanic coupling of steel with polypyrrole coated galvanized steel," in Key Engineering Materials, (Switzerland: Trans Tech Publication), 25-33. doi: 10.4028/www.scientific.net/kem.478.25

Epstein, A., Smallfield, J., Guan, H., and Fahlman, M. (1999). Corrosion protection of aluminum and aluminum alloys by polyanilines: a potentiodynamic and photoelectron spectroscopy study. Synth. Metals 102, 1374-1376. doi: 10.1016/ s0379-6779(98)00383-x

Falk, T., Svensson, J. E., and Johansson, L. G. (1998). The role of carbon dioxide in the atmospheric corrosion of zinc a laboratory study. J. Electrochem. Soc. 145, 39-44. doi: 10.1149/1.1838207

Fasoyinu, F., and Weinberg, F. (1990). Spangle formation in galvanized sheet steel coatings. Metall. Trans. B 21, 549-558. doi: 10.1007/BF02667868

Ferreira, C., Aeiyach, S., Aaron, J. J., and Lacaze, P. (1996). Electrosynthesis of strongly adherent polypyrrole coatings on iron and mild steel in aqueous media. Electrochim. Acta 41, 1801-1809. doi: 10.1016/0013-4686(95)00498-X

Ferreira, M., Duarte, R., Montemor, M., and Simões, A. (2004). Silanes and rare earth salts as chromate replacers for pre-treatments on galvanised steel. Electrochim. Acta 49, 2927-2935. doi: 10.1016/j.electacta.2004.01.051

Figueira, R. B., Silva, C. J., and Pereira, E. V. (2015). Hot-dip galvanized steel dipcoated with ureasilicate hybrid in simulated concrete pore solution: assessment of coating morphology and corrosion protection efficiency. Prog. Org. Coat. 88, 245-255. doi: 10.1016/j.porgcoat.2015.07.008

Figueira, R. B., Silva, C. J., and Pereira, E. V. (2016). Hybrid sol-gel coatings for corrosion protection of galvanized steel in simulated concrete pore solution. J. Coat. Technol. Res. 13, 355-373. doi: 10.1007/s11998-015-9751-7

Figueira, R. B., Silva, C. J., Pereira, E. V., and Salta, M. M. (2013). Ureasilicate hybrid coatings for corrosion protection of galvanized steel in cementitious media. J. Electrochem Soc. 160, C467-C479. doi: 10.1149/2.033310jes

Figueira, R. B., Silva, C. J., Pereira, E. V., and Salta, M. M. (2014). Alcoholaminosilicate hybrid coatings for corrosion protection of galvanized steel in mortar. J. Electrochem. Soc. 161, C349-C362. doi: 10.1149/2.10340 6jes

Francisco, J. S., Capelossi, V. R., and Aoki, I. V. (2014). Evaluation of a sulfursilane anticorrosive pretreatment on galvannealed steel compared to phosphate under a waterborne epoxy coating. Electrochim. Acta 124, 128-136. doi: 10.1016/j. electacta.2013.09.144

Fujita, S., and Mizuno, D. (2007). Corrosion and corrosion test methods of zinc coated steel sheets on automobiles. Corros. Sci. 49, 211-219. doi: 10.1016/j. corsci.2006.05.034

Gandhi, J. S., and van Ooij, W. J. (2004). Improved corrosion protection of aluminum alloys by electrodeposited silanes. J. Mater. Eng. Performance 13, 475-480. doi: 10.1361/10599490420016

Gang, K., Lingyan, L., Jintang, L., Chunshan, C., and Zhong, Z. (2010). Study on lanthanum salt conversion coating modified with citric acid on hot dip galvanized steel. J. Rare Earths 28, 461-465. doi: 10.1016/S1002-0721(09) 60134- 4

Gelling, V. J., Wiest, M. M., Tallman, D. E., Bierwagen, G. P., and Wallace, G. G. (2001). Electroactive-conducting polymers for corrosion control: 4. Studies of poly (3-octyl pyrrole) and poly (3-octadecyl pyrrole) on aluminum 2024-T3 alloy. Prog. Org. Coat. 43, 149-157. doi: 10.1016/S0300-9440(01)00186-2

Gong, L.-H., Tang, R.-R., Zhu, Y.-Q., and Chen, D.-L. (2012). Influence of silane coupling agent on the conversion film forming of galvanized steel treated with cerium salt. Int. J. Min. Metall. Mater. 19, 800-804. doi: 10.1007/s12613-0120631-1

Grundmeier, G., Schmidt, W., and Stratmann, M. (2000). Corrosion protection by organic coatings: electrochemical mechanism and novel methods of investigation. Electrochim. Acta 45, 2515-2533. doi: 10.1016/S0013-4686(00) 00348-0

Haruyama, S., and Sudo, S. (1993). Electrochemical impedance for a large structure in soil. Electrochim. Acta 38, 1857-1865. doi: 10.1016/0013-4686(93)80307-L

Hinton, B., and Wilson, L. (1989). The corrosion inhibition of zinc with cerous chloride. Corros. Sci. 29, 967-985. doi: 10.1016/0010-938x(89)90087-5

Hu, J., Zhang, J., and Cao, C. (2003). Determination of water uptake and diffusion of $\mathrm{Cl}$ - ion in epoxy primer on aluminum alloys in $\mathrm{NaCl}$ solution by electrochemical impedance spectroscopy. Prog. Org. Coat. 46, 273-279. doi: 10.1016/S0300-9440(03)00010-9

Hu, J.-M., Liu, L., Zhang, J.-Q., and Cao, C.-N. (2006). Effects of electrodeposition potential on the corrosion properties of bis-1, 2-[triethoxysilyl] ethane films on aluminum alloy. Electrochim. Acta 51, 3944-3949. doi: 10.1016/j.electacta.2005. 11.008

Hu, J.-M., Liu, L., Zhang, J.-Q., and Cao, C.-N. (2007). Electrodeposition of silane films on aluminum alloys for corrosion protection. Prog. Org. Coat. 58, 265-271. doi: 10.1016/j.porgcoat.2006.11.008

Jafarzadeh, S., Adhikari, A., Sundall, P.-E., and Pan, J. (2011). Study of PANI-MeSA conducting polymer dispersed in UV-curing polyester acrylate on galvanized steel as corrosion protection coating. Prog. Org. Coat. 70, 108-115. doi: 10.1016/ j.porgcoat.2010.10.011

Jia, M.-Z., Zhang, Z., Ruan, and Wu, F.-M. (2013). Corrosion In-hibition action of imidazole derivatives self-assembled films for 316 stainless steel. Surface Technol. 42, 23-27.

Jiang, M.-Y., Wu, L.-K., Hu, J.-M., and Zhang, J.-Q. (2015). Silane-incorporated epoxy coatings on aluminum alloy (AA2024). Part 1: improved corrosion performance. Corros. Sci. 92, 118-126. doi: 10.1016/j.corsci.2014.11.046

Kania, H., and Liberski, P. (2014). "Synergistic influence of the addition of Al, $\mathrm{Ni}$ and $\mathrm{Pb}$ to a zinc bath upon growth kinetics and structure of coatings," in Solid State Phenomena, (Switzerland: Trans Tech Publication), 115-120. doi: 10.4028/www.scientific.net/ssp.212.115

Karaxi, E. K., Kartsonakis, I. A., and Charitidis, C. A. (2019). Assessment of selfhealing epoxy-based coatings containing microcapsules applied on hot dipped galvanized steel. Front. Mater. 6:222. doi: 10.3389/fmats.2019.00222

Kartsonakis, I., Balaskas, A., Koumoulos, E., Charitidis, C., and Kordas, G. (2012). Incorporation of ceramic nanocontainers into epoxy coatings for the corrosion protection of hot dip galvanized steel. Corros. Sci. 57, 30-41. doi: 10.1016/j. corsci.2011.12.037

Kartsonakis, I. A., Stanciu, S. G., Matei, A. A., Hristu, R., Karantonis, A., and Charitidis, C. A. (2016). A comparative study of corrosion inhibitors on hot-dip galvanized steel. Corros. Sci. 112, 289-307. doi: 10.1016/j.corsci.2016.07.030

Keddam, M., Hugot-Le-Goff, A., Takenouti, H., Thierry, D., and Arevalo, M. (1992). The influence of a thin electrolyte layer on the corrosion process of zinc in chloride-containing solutions. Corros. Sci. 33, 1243-1252. doi: 10.1016/0010938X(92)90133-N

Kobayashi, Y., and Fujiwara, Y. (2006). Corrosion protection of cerium conversion coating modified with a self-assembled layer of phosphoric acid mono-n-alkyl ester. Electrochem. Solid State Lett. 9, B15-B18. doi: 10.1149/1.2162328

Koch, G. H., Brongers, M. P., Thompson, N. G., Virmani, Y. P., and Payer, J. H. (2002). Corrosion cost and Preventive Strategies in the United States. Washington, DC: Federal Highway Administration.

Krylova, I. (2001). Painting by electrodeposition on the eve of the 21 st century. Progr. Org. Coat. 42, 119-131. doi: 10.1016/S0300-9440(01)00146-1

Kumar, E., Selvarajan, P., and Muthuraj, D. (2012). Preparation and characterization of polyaniline/cerium dioxide $(\mathrm{CeO} 2)$ nanocomposite via in situ polymerization. J. Mater. Sci. 47, 7148-7156. doi: 10.1007/s10853$012-6655-0$

Le, H. N. T., Garcia, B., Deslouis, C., and Le Xuan, Q. (2001). Corrosion protection and conducting polymers: polypyrrole films on iron. Electrochim. Acta 46, 4259-4272. doi: 10.1016/s0013-4686(01)00699-5 
Li, M., Yang, Y.-Q., Liu, L., Hu, J.-M., and Zhang, J.-Q. (2010). Electro-assisted preparation of dodecyltrimethoxysilane/TiO2 composite films for corrosion protection of AA2024-T3 (aluminum alloy). Electrochim. Acta 55, 3008-3014. doi: 10.1016/j.electacta.2009.12.081

Li, C., Liang, T., Ma, R., Du, A., Fan, Y., Zhao, X., et al. (2020). Superhydrophobic surface containing cerium salt and organosilane for corrosion protection of galvanized steel. J. Alloys Compd. 825:153921. doi: 10.1016/j.jallcom.2020. 153921

Lin, C.-W. (1999). Effect of chromate conversion coatings with and without poly (acrylic acid) on the press formability, shearing properties and durability of galvanized steel laminates using poly (vinyl butyral) as core material. J. Mater. Sci. 34, 3951-3956. doi: 10.1023/A:1004691226931

Liu, Y.-H., Xu, J.-B., Zhang, J.-T., and Hu, J.-M. (2017). Electrodeposited silica film interlayer for active corrosion protection. Corros. Sci. 120, 61-74. doi: 10.1016/j.corsci.2017.01.017

Longhi, M., Kunsta, S. R., Beltrami, L. V. R., Kerstner, E. K., Silva Filho, C. I., Sarmento, V. H. V., et al. (2015). Effect of tetraethoxy-silane (TEOS) amounts on the corrosion prevention properties of siloxane-PMMA hybrid coatings on galvanized steel substrates. Mater. Res. 18, 1140-1155. doi: 10.1590/1516-1439. 321614

Lu, J.-T., Wu, H.-J., Gang, K., Che, C.-S., and Xu, Q.-Y. (2006). Growth and corrosion behavior of rare earth film on hot-dip galvanized steel. Trans. Nonferrous Metal Soc. China 16, 1397-1401. doi: 10.1016/S1003-6326(07) 60027-2

Maaß, P., Peissker, P., and Ahner, C. (2011). Handbook of hot-dip Galvanization. Hoboken, NJ: Wiley Online Library

Maeda, S. (1996). Surface chemistry of galvanized steel sheets relevant to adhesion performance. Prog. Org. Coat. 28, 227-238. doi: 10.1016/0300-9440(95)006 10-9

Mahdavian, M., and Attar, M. (2006). Another approach in analysis of paint coatings with EIS measurement: phase angle at high frequencies. Corros. Sci. 48, 4152-4157. doi: 10.1016/j.corsci.2006.03.012

Maitland, C. (1962). Factors affecting the electrolytic resistance of polymer films. Off. Digest 34:972.

Majd, M. T., Shahrabi, T., and Ramezanzadeh, B. (2019). Low carbon steel surface modification by an effective corrosion protective nanocomposite film based on neodymium-polyacrylic acid-benzimidazole. J. Alloys Compd. 783, 952-968. doi: 10.1016/j.jallcom.2018.12.367

Malekzadeh, M., Sivakugan, N., Kazum, O., and Mathan, B. (2017). Effect of polyaniline-coated galvanized steel electrodes on electrokinetic sedimentation of dredged mud slurries. Can. Geotech. J. 54, 1150-1157. doi: 10.1139/cgj-20160127

Manna, M. (2009). Effect of steel substrate for phosphate treatment: an option to simulate TMT rebar surface. Corros. Sci. 51, 451-457. doi: 10.1016/j.corsci.2008. 11.021

Mansfeld, F., and Tsai, C. (1991). Determination of coating deterioration with EIS: I. basic relationships. Corrosion 47, 958-963. doi: 10.5006/1.3585209

Montemor, M., and Ferreira, M. (2007). Cerium salt activated nanoparticles as fillers for silane films: evaluation of the corrosion inhibition performance on galvanised steel substrates. Electrochim. Acta 52, 6976-6987. doi: 10.1016/j. electacta.2007.05.022

Montemor, M., Rosqvist, A., Fagerholm, H., and Ferreira, M. (2004). The early corrosion behaviour of hot dip galvanised steel pre-treated with bis-1, 2(triethoxysilyl) ethane. Prog. Org. Coat. 51, 188-194. doi: 10.1016/j.porgcoat. 2004.07.011

Montemor, M., Simões, A., and Ferreira, M. (2001). Composition and behaviour of cerium films on galvanised steel. Prog. Org. Coat. 43, 274-281. doi: 10.1016/ S0300-9440(01)00209-0

Montemor, M., Simoes, A., and Ferreira, M. (2002). Composition and corrosion behaviour of galvanised steel treated with rare-earth salts: the effect of the cation. Prog. Org. Coat. 44, 111-120. doi: 10.1016/S0300-9440(01)00250-8

Montemor, M., Simoes, A., Ferreira, M., and Carmezim, M. (2008). Composition and corrosion resistance of cerium conversion films on the AZ31 magnesium alloy and its relation to the salt anion. App. Surface Sci. 254, 1806-1814. doi: 10.1016/j.apsusc.2007.07.187

Montemor, M., Trabelsi, W., Zheludevich, M., and Ferreira, M. (2006). Modification of bis-silane solutions with rare-earth cations for improved corrosion protection of galvanized steel substrates. Prog,. Org. Coat. 57, 67-77. doi: 10.1016/j.porgcoat.2006.06.009

Morimoto, Y., Honda, K., Nishimura, K., Tanaka, S., Takahashi, A., Shindo, H., et al. (2002). Excellent corrosion-resistant Zn-Al-Mg-Si alloy hot-dip galvanized steel sheet "super dyma". Shinnittetsu Giho 22-24.

Motte, C., Poelman, M., Roobroeck, A., Fedel, M., Deflorian, F., and Olivier, M.G. (2012). Improvement of corrosion protection offered to galvanized steel by incorporation of lanthanide modified nanoclays in silane layer. Prog. Org. Coat. 74, 326-333. doi: 10.1016/j.porgcoat.2011.12.001

Naoi, K., Oura Y., Maeda, M., and Nakamura, S. (1995). Electrochemistry of surfactant-doped polypyrrole film(I): formation of columnar structure by electropolymerization. J. Electrochem. Soc. 142:417. doi: 10.1149/1.2044042

Obot, I., Madhankumar, A., Umoren, S., and Gasem, Z. (2015). Surface protection of mild steel using benzimidazole derivatives: experimental and theoretical approach. J. Adhes. Sci. Technol. 29, 2130-2152. doi: 10.1080/01694243.2015. 1058544

Olad, A., and Rasouli, H. (2010). Enhanced corrosion protective coating based on conducting polyaniline/zinc nanocomposite. J. Appl. Polym. Sci. 115, $2221-$ 2227. doi: 10.1002/app.31320

Palanivel, V., Zhu, D., and Ooij, W. J. V. (2003). Nanoparticle-filled silane films as chromate replacements for aluminum alloys. Prog. Org. Coat. 47, 384-392. doi: 10.1016/j.porgcoat.2003.08.015

Pavlidou, E., Pistofidis, N., Vourlias, G., and Stergioudis, G. (2005). Modification of the growth-direction of the zinc coatings associated with element additions to the galvanizing bath. Mater. Lett. 59, 1619-1622. doi: 10.1016/j.matlet.2004. 08.045

Peng, S., Xie, S.-K., Xiao, F., and Lu, J.-T. (2020). Corrosion behavior of spangle on a batch hot-dip galvanized $\mathrm{Zn}-0.05 \mathrm{Al}-0.2 \mathrm{Sb}$ coating in $3.5 \mathrm{wt} . \% \mathrm{NaCl}$ solution. Corros. Sci. 163:108237. doi: 10.1016/j.corsci.2019.108237

Persson, D., Mikhailov, A., and Thierry, D. (2007). In situ studies of the corrosion during drying of confined zinc surfaces. Mat. Corros. 58, 452-462. doi: 10.1002/ maco. 200604029

Pistofidis, N., Vourlias, G., Konidaris, S., Pavlidou, E., and Stergioudis, G. (2007). The combined effect of nickel and bismuth on the structure of hot-dip zinc coatings. Mater. Let. 61, 2007-2010. doi: 10.1016/j.matlet.2006.08.002

Pokorny, P., Kolisko, J., Balik, L., and Novak, P. (2016). Effect of chemical composition of steel on the structure of hot-Dip galvanized coating. Metalurgija $55,115-118$.

Qu, Q., Yan, C., Wan, Y., and Cao, C. (2002). Effects of $\mathrm{NaCl}$ and SO2 on the initial atmospheric corrosion of zinc. Corros. Sci. 44, 2789-2803. doi: 10.1016/S0010938X(02)00076-8

Racicot, R., Brown, R., and Yang, S. C. (1997). Corrosion protection of aluminum alloys by double-strand polyaniline. Synth. Met. 85, 1263-1264. doi: 10.1016/ s0379-6779(97)80232-9

Racicot, R., Clark, R. L., Liu, H. B., Yang, S., Alias, M., and Brown, R. (1995). Anti-corrosion studies of novel conductive polymer coatings on aluminum alloys. MRS Online Proc. Library Arch. 413, 529-534. doi: 10.1557/proc-41 3-529

Roetheli, B., Cox, G., and Littreal, W. (1932). Effect of pH on the corrosion products and corrosion rate of zinc in oxygenated aqueous solutions. Met. Alloys 3, $73-76$.

Rudd, A. L., Breslin, C. B., and Mansfeld, F. (2000). The corrosion protection afforded by rare earth conversion coatings applied to magnesium. Corros. Sci. 42, 275-288. doi: 10.1016/s0010-938x(99)00076-1

Safaeirad, M., Toroghinejad, M., and Ashrafizadeh, F. (2008). Effect of microstructure and texture on formability and mechanical properties of hot-dip galvanized steel sheets. J. Mater. Process. Technol. 196, 205-212. doi: 10.1016/j. jmatprotec.2007.05.035

Schirmeisen, M., and Beck, F. (1989). Electrocoating of iron and other metals with polypyrrole. J. Appl. Electrochem. 19, 401-409. doi: 10.1007/BF0101 5243

Schulz, W., and Thiele, M. (2012). General Hot-Dip Galvanizing. Paris: Eugen, 30-36.

Sekine, I., Sakaguchi, K., and Yuasa, M. (1992). Estimation and prediction of degradation of coating films by frequency at maximum phase angle. J. Coat. Technol. 64, 45-49. 
Sere, P., Culcasi, J. D., Elsner, C. I., and Di Sarli, A. R. (1999). Relationship between texture and corrosion resistance in hot-dip galvanized steel sheets. Surface Coat. Technol. 122, 143-149. doi: 10.1016/s0257-8972(99)00325-4

Seré, P. R., Deyá, C., Egli, W. A., Elsner, C. I., and Di Sarli, A. R. (2014). Protection of galvanized steel with silanes: its comparison with chromium (VI). J. Mater. Eng. Performance 23, 342-348. doi: 10.1007/s11665-013-0746-1

Shacham, R., Avnir, D., and Mandler, D. (1999). Electrodeposition of methylated sol-gel films on conducting surfaces. Adv. Mater. 11, 384-388. doi: 10.1002/ (sici)1521-4095(199903)11:5<384::aid-adma384>3.0.co;2-m

Sheffer, M., Groysman, A., and Mandler, D. (2003). Electrodeposition of sol-gel films on Al for corrosion protection. Corros. Sci. 45, 2893-2904. doi: 10.1016/ S0010-938X(03)00106-9

Shinde, V., Sainkar, S., Gangal, S., and Patil, P. (2006). Synthesis of corrosion inhibitive poly $(2,5$-dimethylaniline) coatings on low carbon steel. J.Mater. Sci. 41, 2851-2858. doi: 10.1007/s10853-006-2375-7

Spinks, G. M., Dominis, A. J., Wallace, G. G., and Tallman, D. E. (2002). Electroactive conducting polymers for corrosion control. J. Solid State Electrochem. 6, 85-100. doi: 10.1007/s100080100211

Strunz, W. (2000). Dielectric relaxation in barrier coatings: a square root of time process. Prog. Org. Coat. 39, 49-60. doi: 10.1016/S0300-9440(00)00099-0

Strutzenberger, J., and Faderl, J. (1998). Solidification and spangle formation of hot-dip-galvanized zinc coatings. Metall. Mater. Trans. A 29, 631-646. doi: 10.1007/s11661-998-0144-8

Su, H.-Y., Chen, P.-L., and Lin, C.-S. (2016). Sol-gel coatings doped with organosilane and cerium to improve the properties of hot-dip galvanized steel. Corros. Sci. 102, 63-71. doi: 10.1016/j.corsci.2015.09.019

Subramanian, V., and Van Ooij, W. (1998). Effect of the amine functional group on corrosion rate of iron coated with films of organofunctional silanes. Corrosion 54, 204-215. doi: 10.5006/1.3284845

Sun, Z. W., Kong, G., Che, C. S., Wang, Y. Q., and Miao, X. R. (2019). Growth behaviour of cerium-based conversion coating on $\mathrm{Zn}-5 \% \mathrm{Al}$ alloy. Surface a Interface Anal. 51, 465-474. doi: 10.1002/sia.6603

Svoboda, J., Kudlacek, J., Kreibich, V., and Legutko, S. (2018). “Alternative methods of chemical pre-treatment on hot-dip galvanization surface for adhesion organic coatings," in Advances in Manufacturing, eds A. Hamrol, O. Ciszak, S. Legutko, and M. Jurczyk, (Berlin: Springer), 687-695. doi: 10.1007/978-3-31968619-6_66

Tallman, D., Pae, Y., and Bierwagen, G. (1999). Conducting polymers and corrosion: polyaniline on steel. Corrosion 55, 779-786. doi: 10.5006/1.3284033

Tallman, D., Pae, Y.-Q., and Bierwagen, G. P. (2000). Conducting polymers and corrosion: part 2-Polyaniline on aluminum alloys. Corrosion 56, 401-410. doi: 10.5006/1.3280544

Tallman, D. E., Spinks, G., Dominis, A., and Wallace, G. G. (2002). Electroactive conducting polymers for corrosion control. J. Solid State Electrochem. 6, 73-84. doi: $10.1007 /$ s100080100211

Tianlan, P., and Ruilin, M. (2009). Rare earth and silane as chromate replacers for corrosion protection on galvanized steel. J. Rare Earths 27, 159-163. doi: 10.1016/S1002-0721(08)60212-4

Tsai, C.-Y., Liu, J.-S., Chen, P.-L., and Lin, C.-S. (2010). A two-step roll coating phosphate/molybdate passivation treatment for hot-dip galvanized steel sheet. Corros. Sci. 52, 3385-3393. doi: 10.1016/j.corsci.2010.06.020

Van Ooij, W., and Child, T. (1998). Protecting metals with silane coupling agents. Chem.Tech. 28:26.

Van Ooij, W., Zhu, D., Prasad, G., Jayaseelan, S., Fu, Y., and Teredesai, N. (2000). Silane based chromate replacements for corrosion control, paint adhesion, and rubber bonding. Surface Eng. 16, 386-396. doi: 10.1179/02670840010151 7369

van Ooij, W. J., and Zhu, D. (2001). Electrochemical impedance spectroscopy of bis-[triethoxysilypropyl] tetrasulfide on Al 2024-T3 substrates. Corrosion 57, 413-427. doi: 10.5006/1.3290365

Van Schaftinghen, T., Le Pen, C., Terryn, H., and Hörzenberger, F. (2004). Investigation of the barrier properties of silanes on cold rolled steel. Electrochim. Acta 49, 2997-3004. doi: 10.1016/j.electacta.2004.01.059

Vincent, G., Bonasso, N., Lecomte, J., Colinet, B., Gay, B., and Esling, C. (2006). The relationship between the fracture toughness and grain boundary characteristics in hot-dip galvanized zinc coatings. J. Mater. Sci. 41, 5966-5975. doi: 10.1007/ s10853-006-0274-6
Vogelsang, J., and Strunz, W. (2001). New interpretation of electrochemical data obtained from organic barrier coatings. Electrochim. Acta 46, 3817-3826. doi: 10.1016/S0013-4686(01)00668-5

Vourlias, G., Pistofidis, N., Stergioudis, G., and Tsipas, D. (2004). The effect of alloying elements on the crystallization behaviour and on the properties of galvanized coatings. Crystal Res. Technol. 39, 23-29. doi: 10.1002/crat. 200310144

Wang, C., Jiang, F., and Wang, F. (2004). The characterization and corrosion resistance of cerium chemical conversion coatings for 304 stainless steel. Corros. Sci. 46, 75-89. doi: 10.1016/S0010-938X(03)00135-5

Weidlich, C., Mangold, K.-M., and Jüttner, K. (2005). EQCM study of the ion exchange behaviour of polypyrrole with different counterions in different electrolytes. Electrochim. Acta 50, 1547-1552. doi: 10.1016/j.electacta.2004.1 0.032

Weng, C.-J., Chang, C.-H., Lin, I.-L., Yeh, J.-M., Wei, Y., Hsu, C.-L., et al. (2012). Advanced anticorrosion coating materials prepared from fluoro-polyanilinesilica composites with synergistic effect of superhydrophobicity and redox catalytic capability. Surface Coat. Technol. 207, 42-49. doi: 10.1016/j.surfcoat. 2012.04.097

Woo, H., Reucroft, P., and Jacob, R. (1993). Electrodeposition of organofunctional silanes and its influence on structural adhesive bonding. J. Adhes. Sci. Technol. 7, 681-697. doi: 10.1163/156856193X00367

Xingwen, Y., Chunan, C., Zhiming, Y., Derui, Z., and Zhongda, Y. (2000). Corrosion behavior of rare earth metal (REM) conversion coatings on aluminum alloy LY12. Mater. Sci. Eng.A 284, 56-63. doi: 10.1016/s09215093(00)00795-4

Xingwen, Y., Chunan, C., Zhiming, Y., Derui, Z., and Zhongda, Y. (2001). Study of double layer rare earth metal conversion coating on aluminum alloy LY12. Corros. Sci. 43, 1283-1294. doi: 10.1016/s0010-938x(00)00 141-4

Xu, J.-B., Cao, Y.-Q., Fang, L., and Hu, J.-M. (2018). A one-step preparation of inhibitor-loaded silica nanocontainers for self-healing coatings. Corros. Sci. 140, 349-362. doi: 10.1016/j.corsci.2018.05.030

Xue, D., and Van Ooij, W. J. (2013). Corrosion performance improvement of hot-dipped galvanized (HDG) steels by electro-deposition of epoxy-resin-ester modified bis-[tri-ethoxy-silyl] ethane (BTSE) coatings. Prog. Org. Coat. 76, 1095-1102. doi: 10.1016/j.porgcoat.2013.03.004

Yalçınkaya, S., Tüken, T., Yazıcı, B., and Erbil, M. (2010). Electrochemical synthesis and corrosion behaviour of poly (pyrrole-co-o-anisidine-co-o-toluidine). Curr.nt Appl. Phys. 10, 783-789. doi: 10.1016/j.cap.2009.09.015

Yamamoto, Y., Nishihara, H., and Aramaki, K. (1993). Self-assembled layers of alkanethiols on copper for protection against corrosion. J. Electrochem. Soc. 140, 436-443. doi: 10.1149/1.2221064

Yang, X., Li, B., Wang, H., and Hou, B. (2010). Anticorrosion performance of polyaniline nanostructures on mild steel. Prog. Org. Coat. 69, 267-271. doi: 10.1016/j.porgcoat.2010.06.004

Yanhua, Z., Zhuang, J., Yongsheng, Y., and Xianguang, Z. (2013). Research on anti-corrosion property of rare earth inhibitor for X70 steel. J. Rare Earths 31, 734-740. doi: 10.1016/S1002-0721(12)60350-0

Yao, B., Wang, G., Ye, J., and Li, X. (2008). Corrosion inhibition of carbon steel by polyaniline nanofibers. Mater. Lett. 62, 1775-1778. doi: 10.1016/j.matlet.2007. 10.001

Yeomans, S. (2004). Galvanized Steel Reinforcement in Concrete. Amsterdam: Elsevier.

Zhang, H., and Zuo, Y. (2008). The improvement of corrosion resistance of $\mathrm{Ce}$ conversion films on aluminum alloy by phosphate posttreatment. Appl. Surface Sci. 254, 4930-4935. doi: 10.1016/j.apsusc.2007. 12.066

Zhang, J., Hu, J., Zhang, J., and Cao, C. (2004). Studies of impedance models and water transport behaviors of polypropylene coated metals in $\mathrm{NaCl}$ solution. Prog. Org. Coat. 49, 293-301. doi: 10.1016/S0300-9440(03)001 15-2

Zhang, S., Yang, B., Kong, G., and Lu, J. (2018). Effect of silicate pretreatment on lanthanum conversion coating of hot-dip galvanized steel. Int. J. Electrochem. Sci. 13, 10247-10258. doi: 10.20964/2018.11.04

Zhang, S. H., Yang, B., Zhai, W., Wang, Z. G., and Li, S. (2019). "Effect of citric acid on cerium conversion coating of hot-dip galvanized steel," in Key Engineering 
Materials, (Switzerland: Trans Tech Publication), 144-151. doi: 10.4028/www. scientific.net/kem.814.144

Zhang, X., and Xu, N. (2007). Predicting life of galvanized steel on internet. Corros. Prot. 28, 49-53. doi: 10.3969/j.issn.1005-748X.2007.01.015

Zhang, Z., Chen, S., Li, Y., Li, S., and Wang, L. (2009). A study of the inhibition of iron corrosion by imidazole and its derivatives self-assembled films. Corros. Sci. 51, 291-300. doi: 10.1016/j.corsci.2008.10.040

Zheludkevich, M. L., Serra, R., Montemor, M. F., and Ferreira, M. G. (2005). Oxide nanoparticle reservoirs for storage and prolonged release of the corrosion inhibitors. Electrochem. Communi. 7, 836-840. doi: 10.1016/j.elecom.2005.04.039

Zhen, F. (2005). Simple Talk About the Forecast Theory About Coating's Life. Beijing: Tsinghua Tongfang Knowledge Network Technology Co., Ltd.

Zhou, C., Lu, X., Xin, Z., and Liu, J. (2013). Corrosion resistance of novel silanefunctional polybenzoxazine coating on steel. Corros Sci. 70, 145-115. doi: 10. 1016/j.corsci.2013.01.023

Zhu, D., and van Ooij, W. J. (2004). Enhanced corrosion resistance of AA 2024-T3 and hot-dip galvanized steel using a mixture of bis-[triethoxysilylpropyl] tetrasulfide and bis-[trimethoxysilylpropyl] amine. Electrochim. Acta 49, 1113-1125. doi: 10.1016/j.electacta.2003.1 0.023

Zuo, Y., Pang, R., Li, W., Xiong, J., and Tang, Y. (2008). The evaluation of coating performance by the variations of phase angles in middle and high frequency domains of EIS. Corros. Sci. 50, 3322-3328. doi: 10.1016/j.corsci.2008.08.049

Conflict of Interest: The authors declare that the research was conducted in the absence of any commercial or financial relationships that could be construed as a potential conflict of interest.

Copyright (c) $2020 \mathrm{Yu}, \mathrm{Hu}$ and Meng. This is an open-access article distributed under the terms of the Creative Commons Attribution License (CC BY). The use, distribution or reproduction in other forums is permitted, provided the original author(s) and the copyright owner(s) are credited and that the original publication in this journal is cited, in accordance with accepted academic practice. No use, distribution or reproduction is permitted which does not comply with these terms. 